\title{
Pricing Strategies of a Three-Stage Supply Chain: A New Research in the Big Data Era
}

\author{
Pan Liu ${ }^{1,2}$ \\ ${ }^{1}$ Economics \& Management College, Henan Agricultural University, NongYe Road 63, Zhengzhou, Henan, China \\ ${ }^{2}$ Chongqing Key Laboratory of Logistics, College of Mechanical Engineering, Chongqing University, Chongqing 400044, China
}

Correspondence should be addressed to Pan Liu; hnycliupan@163.com

Received 27 May 2017; Revised 1 September 2017; Accepted 14 September 2017; Published 24 October 2017

Academic Editor: David Arroyo

Copyright (C) 2017 Pan Liu. This is an open access article distributed under the Creative Commons Attribution License, which permits unrestricted use, distribution, and reproduction in any medium, provided the original work is properly cited.

\begin{abstract}
In the Big Data era, Data Company as the Big Data information (BDI) supplier should be included in a supply chain. In the new situation, to research the pricing strategies of supply chain, a three-stage supply chain with one manufacturer, one retailer, and one Data Company was chosen. Meanwhile, considering the manufacturer contained the internal and external BDI, four benefit models about BDI investment were proposed and analyzed in both decentralized and centralized supply chain using Stackelberg game. Meanwhile, the optimal retail price and benefits in the four models were compared. Findings are as follows. (1) The industry cost improvement coefficient, the internal BDI investment cost of the manufacturer, and the added cost of the Data Company on using Big Data technology have different relationships with the optimal prices of supply chain members in different models. (2) In the retailer-dominated supply chain model, the optimal benefits of the retailer and the manufacturer are the same, and the optimal benefits of the Data Company are biggest in all the members.
\end{abstract}

\section{Introduction}

The era of Big Data has arrived. With the popularity of Internet and mobile Internet, global data are increasing. In addition, the storage cost of these data also reduces following the development of virtual storage and Cloud technology $[1,2]$. In this condition, the development and appliance of Big Data become a possibility. In the Big Data background, data as the necessary original materials of the information economy [3] have infiltrated into every business and influence the development of a business.

Thus, more and more enterprises start to gain and apply Big Data. Some researchers have discussed the merits of Big Data application and think that Big Data have potential values in improving companies' business model [4]. Moreover, Big Data have also huge potential values in improving production ability and efficiency [5]. But, for most companies, handling so complicated and large data is very difficult. To solve these problems, a common choice of companies is to gain Big Data from professional Data Company and buying the related Big Data information (BDI) is their usual behavior. Following this trend growth, Data Company will become an indispensable member of a supply chain. In other words, Data Company should be included in a supply chain.

In these new conditions, if Data Company becomes one of supply chain members, the structure of supply chain will change. Meanwhile, based on our survey in many companies who have applied Big Data plan, they say that their benefits do increase after using Big Data. However, they still want to know how to set a price in this new condition when they are in different game situations. According to the above analyses, previous pricing rules of supply chain members will not be applicable. New pricing rules should be studied considering Data Company. In the new supply chain system, Data Company will pay additional money in Big Data technology or equipment to gain more valuable BDI. In this paper, the manufacturer's BDI includes the external BDI and the internal BDI (the external BDI mainly refers to consumer preference information). Considering the above conditions, how to price to gain more benefits is a vital problem for supply chain members in different game models.

Therefore, aims of this study are to explore pricing strategies of a supply chain considering Data Company in different game situations. Although many studies have explored the 
pricing problem of a supply chain, there is a gap in the related researches in the Big Data environment and considering Data Company as a supply chain member. Thus, in this study, this gap will be made up.

Firstly, the applications of Big Data in supply chain were discussed, and then researches about pricing strategies of supply chain in the Big Data environment were also described. Then, according to the utility function theory, the demand function was constructed. Meanwhile, benefit models were proposed and analyzed in different game models. Finally, the optimal pricing strategies and benefits of supply chain members in different game models were analyzed. Results offer a theoretical guidance for supply chain members pricing strategies in the Big Data environment. Meanwhile, it is a new development of supply chain pricing strategies theory in the Big Data era.

\section{Literature Review}

Following the advent of Big Data era, discussions about the appliance of Big Data in supply chain are increasing. But great majority of them concentrate on the qualitative researches and the quantitative researches are rare; moreover, quantitative researches about pricing problem in the Big Data era are few.

In qualitative aspects, appliances of Big Data have been discussed in supply chain [6-8]. The vitals of Big Data in supply chain management were discussed and more attention about Big Data appliance in a supply chain was invoked [9]. To assist companies utilize Big Data well, a method based on Ramco Cements Limited was presented for implementing Big Data in a firm [10]. Moreover, to combine their competitive advantages with other companies, an analysis mode according to a deduction chart way was proposed [11]. Furthermore, influences of Big Data [12] and its quality [7] on companies' information system are explored. Fosso Wamba et al. thought that companies should understand the values created by Big Data (market segmentation, decision-making, demand discovery, producing new products, etc.) [13]. Furthermore, in the process of using Big Data to make decision, the quality of data collection, analysis, and transmission would affect the decision quality [14]. Meanwhile, Big Data analysis ability had also effects on supply chain performance and organization benefits [15-17]. Hofmann discussed the ability of Big Data on improving some supply chain processes [18]. In this study, "which natures of Big Data has biggest ability on removing the bullwhip effect" was elaborated, finding that the "Velocity" nature has the biggest potential on improving performance. Brinch et al. studied the applications of Big Data in supply chain management processes (manufacturing, logistics, return, sourcing, and planning), finding that the processes of service, planning, and logistics were applicable for implementing Big Data analytics [19]. Lamba and Singh proposed the application trends of Big Data in operations and supply chain management by reviewing current documents [20], findings that, in the manufacturing, logistics, and procurement processes of supply chain, Big Data applications were discussed widely. Big Data can also help company gain more accurate demand signal; in this condition, Niu and
Zou discussed whether the "better demand signal is always good for the supply chain members" [21]. They found that the more accurate demand signal will be better for environment. Chavez et al. explored relationships between manufacturing ability, data-driven supply chains, and customer satisfaction [22], finding that "data-driven supply chains have positive relationships with the manufacturing ability dimensions (i.e., delivery, flexibility, quality, and cost)."

In quantitative aspects, Ji et al. proposed a decisionmaking model of food supply chain using Big Data as input to predict market demand [23]. Badiezadeh et al. proposed a method based on Big Data approach to evaluate the sustainability of supply chain; meanwhile, the double frontier network DEA was also used [24]. Based on Big Data analytic method, Mukherjee and Sinha explored product decisions on recall in medical device supply chain [25]. Here, Big Data method was used to evaluate the judgment Bias. Mani et al. provided a proof in reality to explain the advantages using Big Data analytic method to forecast risk [26]. Yu et al. discussed "how Big Data-driven supply chains influence supply chain abilities" [27]; in this study, they collected related data from Chinese manufactures and the structural equation modelling was also used to explain the effects of data-driven supply chain abilities on financial performance. Olama et al. presented an integral standard model to test the fastness of a firm's data system in the Big Data environment [28]. Tambe applied administrators concentrated on matching relationships between the costs invested in labor and the profits from Big Data [29]. Shi and Li explored the influences of secret information leakage on supply chain member coordination relationship using game theory [30]. Wu et al. discussed the cooperation rules considering Big Data service supplier [31]. Liu and Yi explored the investment decisionmaking and coordination of supply chain on BDI in the information symmetry and asymmetry circumstances [32]. In addition, they discussed the same problem of supply chain on BDI in the decentralized and centralized supply chain [33]. In these researches, the importance of Data Company in a supply chain was underlined and they thought Data Company should be contained in a supply chain.

In the aspects of pricing, from a qualitative view point, Baker and Kiewell discussed how to use Big Data to get a pricing rule, and they proposed that using Big Data analysis technology could get the willingness payment range of consumer [34]. He et al. researched the coordinative pricing policies of retailers in the era of Big Data and discussed how to achieve the multiple dynamic pricing of retailer companies. From a quantitative view point, Liu and Yi explored the pricing policies of green supply chain in the Big Data environment considering targeted advertising and product green degree [35]. However, Data Company was not considered as a supply chain member in their research. In the Big Data environment, Li et al. studied the pricing and production rules of a two-stage supply chain with one manufacturer and two suppliers [36]. However, they did not also consider the importance of Data Company in a supply chain in the Big Data environment.

Based on the aforementioned analyses, we can find that applications of Big Data in supply chain management are 


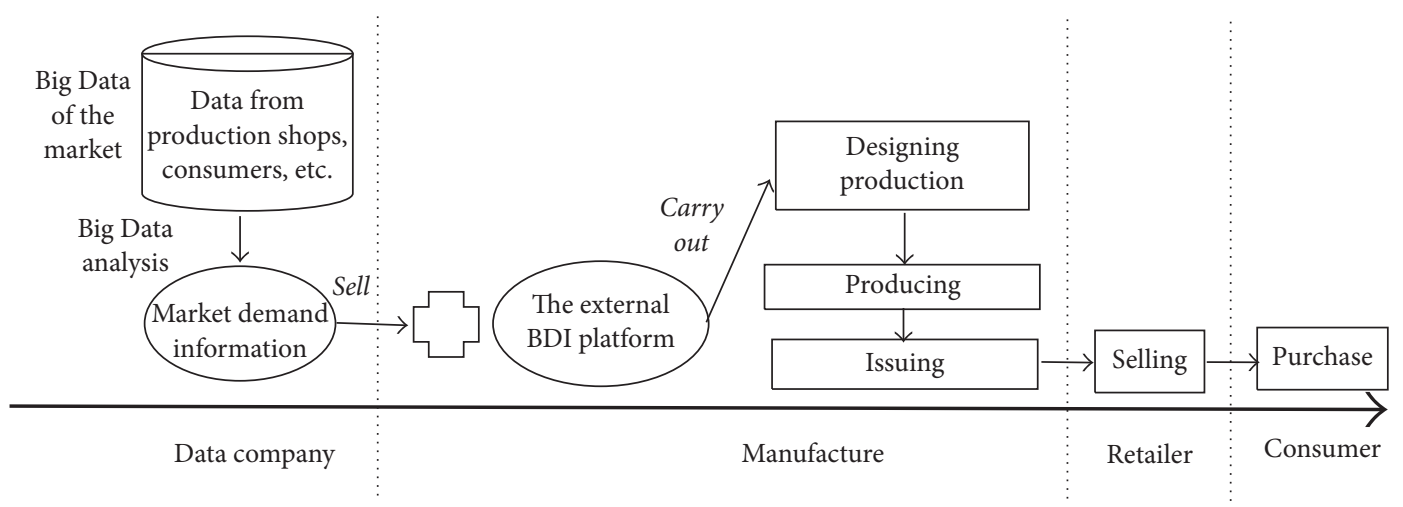

Figure 1: Application of Big Data in the traditional manufacturers.

widely discussed, and pricing strategies of supply chain are also studied from the quantitative and qualitative viewpoints. However, some deficiencies still exist. Previous researches did not consider the importance of Data Company in a supply chain when they discussed pricing policies of supply chain members in the era of Big Data. To make up this gap, in this paper, we will put Data Company into supply chain as a supply chain member and then study the pricing strategies of a three-stage supply chain considering Data Company in decentralized and centralized supply chain. In our research, four game models were proposed in the decentralized and centralized models: (1) Data Company-dominated supply chain model; (2) retailer-dominated supply chain model; (3) manufacturer-dominated supply chain model; (4) the benefit model of the centralized model.

\section{Model Establishment}

In the Big Data environment, following the development of consumer living standards, consumers' heterogeneity preference are added. For manufacturers, getting timely and accurate consumer preference information becomes more and more important. Meanwhile, natures of Big Data can satisfy the requirement of manufacturers on the accurate and timely information. However, Big Data processing is a huge challenge for the IT department of the traditional manufacturers; they usually gain consumer demand information from the related and professional Data Company. According to these preference information, manufacturers design and produce products and these products can satisfy consumer requirement well. But, for Data Company, to obtain more profits from selling consumer BDI, it will add their extra cost in new Big Data analysis technology or equipment. Which effects the growth of these costs and the importance of Data Company in supply chain will have on pricing rules of supply chain is a problem worth exploring. For decision-makers, they also want to know how to price to gain more benefits in different game models. Thus, in this paper, we will do this job.

At present, due to the immature BDI demand market, Data Company-dominated supply chain, retailer-dominated supply chain, manufacturer-dominated supply chain, and centralized supply chain are coexisting. Thus, exploring the pricing rules of these supply chain models has important significance in helping players gain more benefits.

3.1. Variables and Parameters. See "Variables and Parameters" section.

\subsection{Demand Function and Model Assumptions}

3.2.1. Demand Function. In the Big Data environment, to gain more competitive advantages, the manufacturer will buy consumer preference information and then design and produce products to meet consumer demand, and the application of consumer preference information is shown in Figure 1. Thus, the products designed and produced by using consumer preference information will be more able to meet the consumer demands, and consumer will also give a higher value evaluation to the product compared with the condition of not using consumer preference information.

For consumers, they will give their judgment about the product using different value evaluations. We assume that the value evaluation about the product is $v$, and, according to the research of Ferrer and Swaminathan [37], the value evaluation follows the uniform distribution of $[0,1]$. The satisfied degree of consumer heterogeneity demand will affect the value evaluation; assume that the value discount factor is $\alpha$. In different models, the value discount factor is different; thus, the value discount factor in different models is $\alpha^{k}$. In the $N$ model, the value discount factor $\alpha^{N}$ is lower than it in other models. Based on the above analysis and the research of Liu and Yi [33], the utility function $U=\alpha v-p$; here, $v \in[0,1]$. When $U=\alpha v-p>0$, consumers will buy the product. Thus, the demand function $Q=\int_{p / \alpha}^{1} d \nu=1-p / \alpha$, and the market demand formula in different models is shown as follows.

$$
Q^{k}=1-\frac{p^{k}}{\alpha^{k}} .
$$

Typically, both charging by service hours and charging by number of messages are the profit models of the Data Company. In reality, both the two profit models are used. In this paper, the profit model charging by number of messages will be chosen. When the manufacturer obtains these consumer demand information, it can design and produce products 
based on these information. Assume that the total number of consumer information is $D^{k}$ in different models. There is $D^{k}=\beta Q^{k} ; \beta^{k}$ presents the consumer preference information conversion coefficient in different models.

3.2.2. Model Assumptions. (a) In reality, Big Data processing is a huge challenge for the IT department of manufacturers; thus, we assume that the manufacturer obtains consumer demand BDI from the Data Company. Generally, the Data Company charges by number of messages.

(b) The enough production ability is important for manufacturer to face the continuous market demand, and it will also impact the manufacturer's benefit. To highlight the significance of this study and control the effects of the production ability, we assume that the manufacturer has enough production capacity. In addition, to simplify calculation and highlight research significance, many researches assume that supply chain members are completely rational and riskneutral [38]; thus, in this paper, to highlight the significance of this study and control the effects of the players risk appetite, assume that supply chain members are completely rational and risk-neutral.

(c) The manufacturer designs and produces this type product based on the consumer preference information. In addition, different competitive environments will have different market demands; in this paper, we focus on the completely monopolized market.

(d) Generally, consumer preference information is graded by Data Company based on the size and scope of original data or other standards. The price of the information is different at different levels. According to our actual survey, the grade of consumer preference information can reflect the information accuracy, and, for the manufacturer who uses the consumer preference information to design and make products, the information accuracy will influence the satisfaction degree of consumer demand on products. In our paper, parameter $\alpha^{k}$ can reflect the grade difference. In reality, if the price of the information is suitable, the users have a trend to pursue a higher grade. If this trend reaches a balance state, all users will choose the highest grade. Thus, in this paper, we assume that the grade is the same in the proposed four models. Meanwhile, we assume that the manufacturer has the same ability of using consumer BDI, and the products made in the four game models are the same in facing consumer demand (i.e., $\alpha^{\mathrm{DC}}=\alpha^{R}=\alpha^{M}=\alpha^{\mathrm{C}}$ and $\beta^{\mathrm{DC}}=\beta^{R}=\beta^{M}=\beta^{\mathrm{C}}$ ).

\section{Pricing Strategies of the Three-Stage Supply Chain}

In the Big Data environment, to meet consumer demand, manufacturers have to gain consumers' preference information from Data Company. With this trend development, Data Company will become an important part of a supply chain. In this condition, if the supply chain members want to gain more benefits, how should they set a price? When they face different game situation, what should they do? The core of these problems is to explore pricing strategies of a three-stage supply chain considering Data Company in different game situations.
However, in the Big Data environment, most of previous researches on pricing rules of supply chain focus on a twostage supply chain with one manufacturer and one retailer. Few researchers put Data Company into a supply chain as a supply chain member when they study pricing rules of supply chain in the Big Data environment. To solve the above problems and make up the theoretical research gap, a supply chain with one manufacturer, one retailer, and one Data Company was chosen. Based on the utility function theory, the demand function was built. Then, the benefit functions of the manufacturer, the retailer, and the Data Company were constructed in the four models.

4.1. $N$ Model. In the $N$ model, supply chain members pursue their own profit maximization and will not invest in Big Data. Assume that the Data Company is the game leader and first sets the information retail price. The manufacturer sets the product wholesale price considering the information retail price, and then the retailer sets the product retail price.

Thus, in the $N$ model, the benefit functions of the Data Company, the manufacturer, and the retailer are shown in functions (2), (3), and (4), respectively.

$$
\begin{aligned}
& \pi_{b}^{N}\left(p_{b}^{N}\right)=\left(p_{b}^{N}-c_{b}\right) \beta^{N} Q^{N}, \\
& \pi_{d}^{N}\left(w^{N}\right)=\left(w^{N}-p_{b}^{N}-c\right) Q^{N}-p_{b}^{N}\left(\beta^{N}-1\right) Q^{N}, \\
& \pi_{r}^{N}\left(p^{N}\right)=\left(p^{N}-w^{N}\right) Q^{N} .
\end{aligned}
$$

To get the optimal pricing rules of supply chain members, the reverse derivation method is adopted. Firstly, calculating the first-order partial derivative of formula (4) with regard to $p^{N}$, let it be equal to zero. The product retail price with regard to $w^{N}$ can be obtained.

$$
p^{N}\left(w^{N}\right)=\frac{\alpha^{N}+w^{N}}{2} .
$$

Then, putting $p^{N}\left(w^{N}\right)$ into formula (3), we calculate the first-order partial derivative of $\pi_{d}^{N}\left(w^{N}\right)$ with regard to $w^{N}$ and let it be equal to zero. The product wholesale price can be obtained.

$$
w^{N}\left(p_{b}^{N}\right)=\frac{\alpha^{N}+\beta^{N} p_{b}^{N}+c}{2} .
$$

Then, according to formulas (5) and (6), we get

$$
\begin{aligned}
& \left(p_{b}^{N *}, w^{N *}, p^{N *}, Q^{N *}\right)=\left(\frac{\alpha^{N}-c+\beta^{N} c_{b}}{2 \beta^{N}},\right. \\
& \left.\quad \frac{3 \alpha^{N}+c+\beta^{N} c_{b}}{4}, \frac{7 \alpha^{N}+c+\beta^{N} c_{b}}{8}, \frac{\alpha^{N}-c-\beta^{N} c_{b}}{8 \alpha^{N}}\right) .
\end{aligned}
$$

Due to $Q^{N}>0, \alpha^{N}$ should be bigger than $c+\beta^{N} c_{b}$; namely,

$$
c+\beta c_{b}<\alpha^{\mathrm{DC}} .
$$


Based on formula (7), we get supply chain members' benefits.

$$
\begin{gathered}
\left(\pi_{b}^{N *}, \pi_{d}^{N *}, \pi_{r}^{N *}\right)=\left(\frac{\left(\alpha^{N}-c-\beta^{N} c_{b}\right)^{2}}{16 \alpha^{N}},\right. \\
\left.\frac{\left(\alpha^{N}-c-\beta^{N} c_{b}\right)^{2}}{32 \alpha^{N}}, \frac{\left(\alpha^{N}-c-\beta^{N} c_{b}\right)^{2}}{64 \alpha^{N}}\right) .
\end{gathered}
$$

According to formulas (7) and (9), Proposition 1 is obtained.

\section{Proposition 1.}

(1) $\partial p_{b}^{N *} / \partial c_{b i}=0, \partial w^{N *} / \partial c_{b i}=0, \partial p^{N *} / \partial c_{b i}=0$.

(2) $\partial p_{b}^{N *} / \partial c_{d}=0, \partial w^{N *} / \partial c_{d}=0, \partial p^{N *} / \partial c_{d}=0$.

(3) $\partial p_{b}^{N *} / \partial \theta=0, \partial w^{N *} / \partial \theta=0, \partial p^{N *} / \partial \theta=0$.

(4) $\partial p_{b}^{N *} / \partial \beta^{N}=c_{b} / 2>0, \partial w^{N *} / \partial \beta^{N}=c_{b} / 4>0, \partial p^{N *} /$ $\partial \beta^{N}=c_{b} / 8>0$.

Based on Proposition 1, we can get that, with the cost growth of the Data Company investing in Big Data technology $\left(c_{b i}\right)$, the manufacturer internal BDI cost $\left(c_{d}\right)$, and the industry cost improvement coefficient $(\theta)$, the optimal BDI retail price, the optimal product retail price, and the optimal wholesale price have no changes. With the increase of the consumer preference information conversion coefficient $\left(\beta^{N}\right)$, the optimal BDI retail price, the optimal product retail price, and the optimal wholesale price will grow. Moreover, regarding the change of $\beta^{N}$, the optimal BDI retail price is more sensitive. It indicates that increasing the consumer preference information conversion rate will help the Data Company set a high retail price and gain more benefits.

4.2. DC Model. In the DC model, supply chain members pursue their own profit maximization. We assume that the Data Company is the game leader and first sets the BDI retail price. The manufacturer sets the wholesale price of productions considering the BDI retail price, and then the retailer sets the product retail price.

In the DC model, the Data Company has used Big Data technology to extract information; thus, the accuracy of consumer preference information is high, if the manufacturer purchases consumer preference information from the Data Company, and then produces products according to these information. The product can meet the needs of consumers well. Thus, in the DC model, the benefit functions of the Data Company, the manufacturer, and the retailer are shown in functions (10), (11), and (12), respectively.

$$
\begin{aligned}
\pi_{b}^{\mathrm{DC}}\left(p_{b}^{\mathrm{DC}}\right)= & \left(p_{b}^{\mathrm{DC}}-c_{b i}-\theta c_{b}\right) \beta^{\mathrm{DC}} Q^{\mathrm{DC}}, \\
\pi_{d}^{\mathrm{DC}}\left(w^{\mathrm{DC}}\right)= & \left(w^{\mathrm{DC}}-p_{b}^{\mathrm{DC}}-c_{d}-\theta c\right) Q^{\mathrm{DC}} \\
& -p_{b}^{\mathrm{DC}}\left(\beta^{\mathrm{DC}}-1\right) Q^{\mathrm{DC}}, \\
\pi_{r}^{\mathrm{DC}}\left(p^{\mathrm{DC}}\right)= & \left(p^{\mathrm{DC}}-w^{\mathrm{DC}}\right) Q^{\mathrm{DC}} .
\end{aligned}
$$

To get the optimal pricing rules of supply chain members, the reverse derivation method is adopted. Firstly, calculating the first-order partial derivative of formula (12) with regard to $p^{\mathrm{DC}}$, let it be equal to zero. The product retail price with regard to $w^{\mathrm{DC}}$ can be obtained.

$$
p^{\mathrm{DC}}\left(w^{\mathrm{DC}}\right)=\frac{\alpha^{\mathrm{DC}}+w^{\mathrm{DC}}}{2} \text {. }
$$

Then, putting $p^{\mathrm{DC}}\left(w^{\mathrm{DC}}\right)$ into formula (11), we calculate the first-order partial derivative of $\pi_{d}^{\mathrm{DC}}\left(w^{\mathrm{DC}}\right)$ with regard to $w^{\mathrm{DC}}$ and let it be equal to zero. The product wholesale price can be obtained.

$$
w^{\mathrm{DC}}\left(p_{b}^{\mathrm{DC}}\right)=\frac{\alpha+c_{d}+\beta^{\mathrm{DC}} p_{b}^{\mathrm{DC}}+\theta c}{2} .
$$

Then, according to formulas (13) and (14), we get

$$
\begin{aligned}
& \left(p_{b}^{\mathrm{DC} *}, w^{\mathrm{DC} *}, p^{\mathrm{DC} *}, Q^{\mathrm{DC} *}\right) \\
& =\left(\frac{\alpha^{\mathrm{DC}}-\theta c-c_{d}+\beta^{\mathrm{DC}} c_{b i}+\beta^{\mathrm{DC}} \theta c_{b}}{2 \beta^{\mathrm{DC}}},\right. \\
& \frac{3 \alpha^{\mathrm{DC}}+\theta c+c_{d}+\beta^{\mathrm{DC}} c_{b i}+\beta^{\mathrm{DC}} \theta c_{b}}{4}, \\
& \frac{7 \alpha^{\mathrm{DC}}+\theta c+c_{d}+\beta^{\mathrm{DC}} c_{b i}+\beta^{\mathrm{DC}} \theta c_{b}}{8}, \\
& \left.\frac{\alpha^{\mathrm{DC}}-\theta c-c_{d}-\beta^{\mathrm{DC}} c_{b i}-\beta^{\mathrm{DC}} \theta c_{b}}{8 \alpha^{\mathrm{DC}}}\right) .
\end{aligned}
$$

Due to $Q^{\mathrm{DC}}>0, \alpha^{\mathrm{DC}}$ should be bigger than $\theta c+c_{d}+$ $\beta^{\mathrm{DC}} \theta c_{b}+\beta^{\mathrm{DC}} c_{b i} ;$ namely,

$$
c_{d}+\beta^{\mathrm{DC}} c_{b i}<\alpha^{\mathrm{DC}}-\theta c-\beta \theta c_{b} .
$$

Based on formula (15), we get supply chain members' benefits.

$$
\begin{aligned}
& \left(\pi_{b}^{\mathrm{DC} *}, \pi_{d}^{\mathrm{DC} *}, \pi_{r}^{\mathrm{DC} *}\right) \\
& =\left(\frac{\left(\alpha^{\mathrm{DC}}-\theta c-c_{d}-\beta^{\mathrm{DC}} \theta c_{b}-\beta^{\mathrm{DC}} c_{b i}\right)^{2}}{16 \alpha^{\mathrm{DC}}},\right. \\
& \quad \frac{\left(\alpha^{\mathrm{DC}}-\theta c-c_{d}-\beta^{\mathrm{DC}} \theta c_{b}-\beta^{\mathrm{DC}} c_{b i}\right)^{2}}{32 \alpha^{\mathrm{DC}}}, \\
& \left.\frac{\left(\alpha^{\mathrm{DC}}-\theta c-c_{d}-\beta^{\mathrm{DC}} \theta c_{b}-\beta^{\mathrm{DC}} c_{b i}\right)^{2}}{64 \alpha^{\mathrm{DC}}}\right) .
\end{aligned}
$$

According to formulas (15) and (17), Proposition 2 is obtained.

\section{Proposition 2.}

(1) $\partial p_{b}^{D C *} / \partial c_{b i}=1 / 2>0, \partial w^{D C *} / \partial c_{b i}=\beta^{D C} / 4>0$, $\partial p^{D C *} / \partial c_{b i}=\beta^{D C} / 8>0$. 
(2) $\partial p_{b}^{D C *} / \partial c_{d}=-1 / 2 \beta^{D C}<0, \partial w^{D C *} / \partial c_{d}=1 / 4>0$, $\partial p^{D C *} / \partial c_{d}=1 / 8>0$.

(3) $\partial p_{b}^{D C *} / \partial \theta=\left(\beta^{D C} c_{b}-c\right) / 2 \beta^{D C}, \partial w^{D C *} / \partial \theta=\left(\beta^{D C} c_{b}+\right.$ c) $/ 4>0, \partial p^{D C *} / \partial \theta=\left(\beta^{D C} c_{b}+c\right) / 8>0$.

(4) $\partial p_{b}^{D C *} / \partial \beta^{D C}=\left(\theta c_{b}+c_{b i}\right) / 2, \partial w^{D C *} / \partial \beta^{D C}=\left(\theta c_{b}+c_{b i}\right) /$ $4>0, \partial p^{D C *} / \partial \beta^{D C}=\left(\theta c_{b}+c_{b i}\right) / 8>0$.

Based on Proposition 2, we can get that, with the cost growth of the Data Company investing in Big Data technology, the optimal BDI retail price, the optimal product retail price, and the optimal wholesale price will increase. Maybe it is because the manufacturer has to set a high retail price to make up for the added cost invested in Big Data technology to gain more benefits. Facing the growth of the BDI retail price, the manufacturer has to increase its product wholesale price to obtain more benefits, and then the retailer will also set a higher product retail price because of the growth of the wholesale price. However, when $\beta^{\mathrm{DC}}<2$, about the changes of $c_{b i}$, the optimal BDI retail price is more sensitive. Maybe it is because the Data Company bears all the cost investing in Big Data technology, when the cost adds one unit, the BDI retail price will add 0.5 units.

With the growth of the manufacturer internal BDI cost $\left(c_{d}\right)$, the optimal product retail price and the optimal wholesale price will increase; however, the optimal retail price of the Data Company will decrease. Maybe it is because the manufacturer has to set a high wholesale price to make up its internal BDI investment costs; with the increase of the wholesale price, the retailer has to set a higher retail price. To sell more consumer BDI and gain more benefits, the Data Company may reduce its consumer BDI retail price.

With the growth of the industry cost improvement coefficient $(\theta)$, the optimal product retail price and the optimal wholesale price will increase; however, changes of the optimal BDI retail price depend on the difference value between the information production cost of the Data Company and the product production cost of the manufacturer. When the information production cost of the Data Company is higher than the product production cost of the manufacturer, the optimal BDI retail price will grow; otherwise, it will reduce.

With the increase of the consumer preference information conversion coefficient $\left(\beta^{\mathrm{DC}}\right)$, the optimal BDI retail price, the optimal product retail price, and the optimal wholesale price will grow. Moreover, regarding the change of $\beta^{\mathrm{DC}}$, the optimal BDI retail price is more sensitive. It indicates that increasing the consumer preference information conversion rate will help the Data Company set a high retail price and gain more benefits.

In addition, when the upstream members of supply chain invest and use Big Data, for the downstream members, its wholesale price or retail price will increase. It indicates that when the upstream members of supply chain invest and use Big Data, the costs invested in Big Data will pass to the downstream members with the style of wholesale price or consumer BDI retail price.

4.3. $R$ Model. In the $R$ model, the retailer is the leader. The dynamic game order of supply chain members is as follows: the retailer decides the product retail price, and then the Data Company decides the consumer BDI retail price; finally, the manufacturer decides the wholesale price. The product can meet the needs of consumers well. Thus, the benefit functions of the Data Company, the manufacturer, and the retailer are shown in functions (18), (19), and (20), respectively.

$$
\begin{aligned}
\pi_{b}^{R}\left(p_{b}^{R}\right)= & \left(p_{b}^{R}-c_{b i}-\theta c_{b}\right) \beta^{R} Q^{R} \\
\pi_{d}^{R}\left(w^{R}\right)= & \left(w^{R}-p_{b}^{R}-c_{d}-\theta c\right) Q^{R} \\
& -p_{b}^{R}\left(\beta^{R}-1\right) Q^{R} \\
\pi_{r}^{R}\left(p^{R}\right)= & \left(p^{R}-w^{R}\right) Q^{R}
\end{aligned}
$$

To get the optimal pricing rules of supply chain members, the reverse derivation method is adopted. Firstly, to facilitate the computation, let $p^{R}=w^{R}+x$; then put it into formula (19). The calculation method is similar to Section 4.1; thus, we will not repeat it. Based on formulas (18), (19), and (20), we get

$$
\begin{aligned}
& \left(p_{b}^{R *}, w^{R *}, p^{R *}, Q^{R *}\right) \\
& =\left(\frac{2 \alpha^{R}-2 \theta c-2 c_{d}+3 \beta^{R} c_{b i}+3 \beta^{R} \theta c_{b}}{5 \beta^{R}},\right. \\
& \quad \frac{3 \alpha^{R}+2 \theta c+2 c_{d}+2 \beta^{R} c_{b i}+2 \beta^{R} \theta c_{b}}{5}, \\
& \frac{4 \alpha^{R}+\theta c+c_{d}+\beta^{R} c_{b i}+\beta^{R} \theta c_{b}}{5}, \\
& \left.\frac{\alpha^{R}-\theta c-c_{d}-\beta^{R} c_{b i}-\beta^{R} \theta c_{b}}{5 \alpha^{R}}\right) .
\end{aligned}
$$

Due to $Q^{R}>0, \alpha^{R}$ should be bigger than $\theta c+c_{d}+\beta^{R} \theta c_{b}+\beta^{R} c_{b i}$; namely,

$$
c_{d}+\beta^{R} c_{b i}<\alpha^{R}-\theta c-\beta^{R} \theta c_{b}
$$

Based on formula (21), supply chain members' benefits are

$$
\begin{aligned}
& \left(\pi_{b}^{R *}, \pi_{d}^{R *}, \pi_{r}^{R *}\right) \\
& \quad=\left(\frac{2\left(\alpha^{R}-\theta c-c_{d}-\beta^{R} \theta c_{b}-\beta^{R} c_{b i}\right)^{2}}{25 \alpha^{R}},\right. \\
& \quad \frac{\left(\alpha^{R}-\theta c-c_{d}-\beta^{R} \theta c_{b}-\beta^{R} c_{b i}\right)^{2}}{25 \alpha^{R}} \\
& \left.\quad \frac{\left(\alpha^{R}-\theta c-c_{d}-\beta^{R} \theta c_{b}-\beta^{R} c_{b i}\right)^{2}}{25 \alpha^{R}}\right) .
\end{aligned}
$$

According to formulas (21) and (23), Proposition 3 is obtained. 


\section{Proposition 3.}

(1) $\partial p_{b}^{R *} / \partial c_{b i}=3 / 5>0, \partial w^{R *} / \partial c_{b i}=2 \beta^{R} / 5>0, \partial p^{R *} /$ $\partial c_{b i}=\beta^{R} / 5>0$.

(2) $\partial p_{b}^{R *} / \partial c_{d}=-2 / 5 \beta^{R}<0, \partial w^{R *} / \partial c_{d}=2 / 5>0, \partial p^{R *} /$ $\partial c_{d}=1 / 5>0$.

(3) $\partial p_{b}^{R *} / \partial \theta=\left(3 \beta^{R} c_{b}-2 c\right) / 5 \beta^{R}, \partial w^{R *} / \partial \theta=\left(2 \beta^{R} c_{b}+2 c\right) /$ $5>0, \partial p^{R *} / \partial \theta=\left(\beta^{R} c_{b}+c\right) / 5>0$.

(4) $\partial p_{b}^{R *} / \partial \beta^{R}=\left(3 \theta c_{b}+3 c_{b i}\right) / 5, \partial w^{R *} / \partial \beta^{R}=\left(2 \theta c_{b}+2 c_{b i}\right) /$ $5>0, \partial p^{R *} / \partial \beta^{R}=\left(\theta c_{b}+c_{b i}\right) / 5>0$.

Proposition 3 shows that, with the cost growth of the Data Company invested in Big Data technology, the optimal BDI retail price, the optimal product retail price, and the optimal wholesale price will increase in the $R$ model. Moreover, about the change of $c_{b i}$, the optimal BDI retail price, the optimal product retail price, and the optimal wholesale price in the $R$ model are more sensitive than they are in the DC model. Maybe it is because, in the DC model, the Data Company can control its investment costs in Big Data technology well.

With the growth of the manufacturer internal BDI cost $\left(c_{d}\right)$, the optimal product retail price and the optimal wholesale price will increase; however, the optimal BDI retail price will decrease. Moreover, about the change of $c_{d}$, the optimal wholesale price and the optimal BDI retail price in the $R$ model are less sensitive than they in the DC model. The optimal product retail price in the $R$ model is more sensitive than it in the DC model. Maybe it is because, in the aspect of coordinating the external BDI investment of the manufacturer, the Data Company as the leader in the DC model is not as good as the retailer as the leader in the $R$ model.

With the growth of the industry cost improvement coefficient $(\theta)$, the optimal product retail price and the optimal wholesale price will increase; however, changes of the optimal BDI retail price depend on the difference value between the information production cost of the Data Company and the product production cost of the manufacturer. Moreover, about the change of $\theta$, the optimal wholesale price, the optimal BDI retail price, and the optimal retail price in the $R$ model are more sensitive than they are in the DC model. It indicates that the industry cost improvement coefficient has more effects on decision-makers' pricing rules in the $R$ model.

With the increase of the consumer preference information conversion coefficient $\left(\beta^{R}\right)$, the optimal BDI retail price, the optimal product retail price, and the optimal wholesale price will grow. Moreover, regarding the change of $\beta^{R}$, the optimal BDI retail price is more sensitive. It indicates that increasing the consumer preference information conversion rate will help the Data Company set a high retail price and gain more benefits. However, regarding the change of $\beta^{R}$, supply chain members optimal pricing in the $R$ model is more sensitive than it is in the DC model. It shows that effects of $\beta^{R}$ on supply chain members pricing rules are different in different decision order.

4.4. $M$ Model. In the $M$ model, the manufacturer is the leader. The dynamic game order of supply chain members is as follows: the manufacturer decides the wholesale price, and then the Data Company decides the consumer BDI retail price and the retailer decides the product retail price. Thus, the benefit functions of the Data Company, the manufacturer, and the retailer are shown in functions (24), (25), and (26), respectively.

$$
\begin{aligned}
\pi_{b}^{M}\left(p_{b}^{M}\right)= & \left(p_{b}^{M}-c_{b i}-\theta c_{b}\right) \beta^{M} Q^{M} \\
\pi_{d}^{M}\left(w^{M}\right)= & \left(w^{M}-p_{b}^{M}-c_{d}-\theta c\right) Q^{M} \\
& -p_{b}^{M}\left(\beta^{M}-1\right) Q^{M} \\
\pi_{r}^{M}\left(p^{M}\right)= & \left(p^{M}-w^{M}\right) Q^{M}
\end{aligned}
$$

To get the optimal pricing rules of supply chain members, the reverse derivation method is adopted. Firstly, to facilitate the computation, let $w^{M}=p_{b}^{M}+\theta c+c_{d}+x$. The calculation method is similar to Section 4.1; thus, we will not repeat it. Based on formulas (24), (25), and (26), we get

$$
\begin{aligned}
\left(p_{b}^{M *}, w^{M *}, p^{M *}, Q^{M *}\right) & \\
= & \left(\frac{\alpha^{M}-\theta c-c_{d}+2 \beta^{M} c_{b i}+2 \beta^{M} \theta c_{b}}{3 \beta^{M}},\right. \\
& \frac{2 \alpha^{M}+\theta c+c_{d}+\beta^{M} c_{b i}+\beta^{M} \theta c_{b}}{3}, \\
& \frac{5 \alpha^{M}+\theta c+c_{d}+\beta^{M} c_{b i}+\beta^{M} \theta c_{b}}{6}, \\
& \left.\frac{\alpha^{M}-\theta c-c_{d}-\beta^{M} c_{b i}-\beta^{M} \theta c_{b}}{6 \alpha^{M}}\right) .
\end{aligned}
$$

Due to $Q^{M}>0, \alpha^{M}$ should be bigger than $\theta c+c_{d}+\beta^{M} \theta c_{b}+$ $\beta^{M} c_{b i}$; namely,

$$
c_{d}+\beta^{M} c_{b i}<\alpha^{M}-\theta c-\beta^{M} \theta c_{b}
$$

Based on formula (27), supply chain members' benefits are

$$
\begin{aligned}
\left(\pi_{b}^{M *}, \pi_{d}^{M *}, \pi_{r}^{M *}\right) & \\
= & \left(\frac{\left(\alpha^{M}-\theta c-c_{d}-\beta^{M} \theta c_{b}-\beta^{M} c_{b i}\right)^{2}}{18 \alpha^{M}},\right. \\
& \frac{\left(\alpha^{M}-\theta c-c_{d}-\beta^{M} \theta c_{b}-\beta^{M} c_{b i}\right)^{2}}{18 \alpha^{M}} \\
& \left.\frac{\left(\alpha^{M}-\theta c-c_{d}-\beta^{M} \theta c_{b}-\beta^{M} c_{b i}\right)^{2}}{36 \alpha^{M}}\right) .
\end{aligned}
$$

According to formulas (27) and (29), Proposition 4 is obtained. 


\section{Proposition 4.}

(1) $\partial p_{b}^{M *} / \partial c_{b i}=2 / 3>0, \partial w^{M *} / \partial c_{b i}=\beta^{M} / 3>0, \partial p^{M *} /$ $\partial c_{b i}=\beta^{M} / 6>0$.

(2) $\partial p_{b}^{M *} / \partial c_{d}=-1 / 3 \beta^{M}<0, \partial w^{M *} / \partial c_{d}=1 / 3>0$, $\partial p^{M *} / \partial c_{d}=1 / 6>0$.

(3) $\partial p_{b}^{M *} / \partial \theta=\left(2 \beta^{M} c_{b}-c\right) / 3 \beta^{M}, \partial w^{M *} / \partial \theta=\left(\beta^{M} c_{b}+c\right) /$ $3>0, \partial p^{M *} / \partial \theta=\left(\beta^{M} c_{b}+c\right) / 6>0$.

(4) $\partial p_{b}^{M *} / \partial \beta^{M}=\left(2 \theta c_{b}+2 c_{b i}\right) / 3, \partial w^{M *} / \partial \beta^{M}=\left(\theta c_{b}+c_{b i}\right) /$ $3>0, \partial p^{M *} / \partial \beta^{M}=\left(\theta c_{b}+c_{b i}\right) / 6>0$.

Proposition 4 shows that, with the cost growth of the Data Company invested in Big Data technology, the optimal BDI retail price, the optimal product retail price, and the optimal wholesale price will increase in the $M$ model. Moreover, regarding the change of $c_{b i}$, the optimal wholesale price and the optimal retail price in the $M$ model are more sensitive than they are in the DC model and less sensitive than they are in the $R$ model. However, about the change of $c_{b i}$, the optimal retail price of the Data Company in the $M$ model is more sensitive among the above three models. Maybe it is because, in the DC model, the Data Company can control its investment costs in Big Data technology well.

With the growth of the manufacturer internal BDI cost $\left(c_{d}\right)$, the optimal product retail price and the optimal wholesale price will increase; however, the optimal BDI retail price will decrease. Moreover, about the change of $c_{d}$, the optimal wholesale price and the optimal product retail price in the $M$ model are less sensitive than they are in the $R$ model and are more sensitive than they are in the DC model. However, regarding the change of $c_{d}$, the optimal retail price of the Data Company in the $M$ model is the less sensitive among the above three models. Maybe it is because, in the aspect of coordinating the external BDI investment of the manufacturer, the retailer as the leader in the $R$ model is not as good as the manufacturer as the leader in the $M$ model.

With the growth of the industry cost improvement coefficient $(\theta)$, the optimal product retail price and the optimal wholesale price will increase; however, changes of the optimal BDI retail price depend on the difference value between the information production cost of the Data Company and the product production cost of the manufacturer. Moreover, about the change of $\theta$, the optimal wholesale price and the optimal product retail price in the $M$ model are less sensitive than they are in the $R$ model and are more sensitive than they are in the DC model. However, regarding the change of $\theta$, the optimal BDI retail price in the $M$ model is most sensitive among the above three models. It indicates that the industry cost improvement coefficient has more effects on pricing aspects of the Data Company in the $M$ model.

With the increase of the consumer preference information conversion coefficient $\left(\beta^{M}\right)$, the optimal BDI retail price, the optimal product retail price, and the optimal wholesale price will grow. Moreover, regarding the change of $\beta^{M}$, the optimal BDI retail price is more sensitive. It indicates that increasing the consumer preference information conversion rate will help the Data Company set a high retail price and gain more benefits. However, regarding the change of $\beta^{M}$, supply chain members optimal pricing in the $M$ model is less sensitive than it is in models of $R$ and DC. It shows that effects of $\beta^{M}$ on supply chain members pricing rules are different in different decision order.

4.5. $C$ Model. In the $C$ model, the benefit function of the centralized supply chain is shown in

$$
\pi_{j}^{C}=\left(p^{C}-\theta c-c_{d}-\beta^{C} c_{b i}-\beta^{C} \theta c_{b}\right) Q^{C} .
$$

Based on formula (30), we get

$$
\begin{gathered}
\left(p^{C *}, Q^{C *}\right)=\left(\frac{\alpha^{C}+\theta c+\theta \beta^{C} c_{b}+c_{d}+\beta^{C} c_{b i}}{2},\right. \\
\left.\frac{\alpha^{C}-\theta c-\theta \beta^{N C} c_{b}-c_{d}-\beta^{C} c_{b i}}{2 \alpha^{C}}\right) .
\end{gathered}
$$

Due to $Q^{C}>0, \alpha^{C}$ should be bigger than $\theta c+\theta \beta^{C} c_{b}+c_{d}+$ $\beta^{C} c_{b i}$; namely,

$$
\alpha^{C}-\theta c-\theta \beta^{C} c_{b}>c_{d}+\beta^{C} c_{b i} .
$$

Based on formula (31), supply chain benefit is

$$
\pi_{j}^{C *}=\frac{\left(\alpha^{C}-\theta c-\theta \beta^{C} c_{b}-c_{d}-\beta^{C} c_{b i}\right)^{2}}{4 \alpha^{C}} .
$$

According to formula (31), Proposition 5 is obtained.

\section{Proposition 5.}

(1) $\partial p^{C *} / \partial c_{b i}=\beta^{C} / 2>0, \partial p^{C *} / \partial c_{d}=1 / 2>$ $0, \partial p^{C *} / \partial \theta=\left(c+\beta^{C} c_{b}\right) / 2>0, \partial p^{C *} / \partial \beta^{C}=\left(c_{b i}+\right.$ $\left.\theta c_{b}\right) / 2>0$.

Proposition 5 indicates that the retail price has a positive relationship with the cost of the Data Company investing in Big Data technology $\left(c_{b i}\right)$, the cost of the internal BDI cost of the manufacturer $\left(c_{d}\right)$, and the industry cost improvement coefficient $(\theta)$. Moreover, about the change of the Data Company investing in Big Data technology $\left(c_{b i}\right)$, the sensitivity of the optimal retail price in the $C$ model is related to $\beta^{C}$. Namely, the bigger the consumer preference information conversion coefficient, the bigger the optimal retail price. In addition, about the change of the industry cost improvement coefficient $(\theta)$, the sensitivity of the optimal retail price in the $C$ model is also related to $\beta^{C}$. Namely, the lower the industry cost improvement coefficient, the lower the optimal retail price.

With the increase of the consumer preference information conversion coefficient $\left(\beta^{C}\right)$, the optimal product retail price will grow. However, regarding the change of $\beta^{C}$, supply chain members optimal pricing in the $M$ model is less sensitive than it in models of $R, C$, and DC. It shows that effects of $\beta^{C}$ on supply chain members pricing rules are different in different decision order. 
The above analyses indicate that the consumer preference information conversion coefficient will affect the pricing strategies of decision-maker in the $C$ model. Thus, for the decision-maker, they should improve the consumer preference information conversion coefficient in the application process of Big Data.

4.6. Prices and Benefits Contrast in the Four Models. Based on the aforementioned four competition models, Table 1 was obtained.

Proposition 6. There are the following relationships: when $7\left(\alpha^{N}-\alpha^{D C}\right)+(1-\theta) c+\left(\beta^{N}-\beta^{D C}\right) c_{b}-c_{d}>0, p^{N *}>p^{D C *}>$ $p^{M *}>p^{R *}>p^{C *}$; when $3\left(\alpha^{N}-\alpha^{D C}\right)+(1-\theta) c+\left(\beta^{N}-\right.$ $\left.\beta^{D C}\right) c_{b}-c_{d}>0, w^{N *}>w^{D C *}>w^{M *}>w^{R *}$; when $\beta^{D C}\left(\alpha^{N-}\right.$ $\left.c+\beta^{N} c_{b}\right)-\beta^{N}\left(\alpha^{D C}-\theta c-c_{d}+\beta^{D C} c_{b i}+\beta^{D C} \theta c_{b}\right), p_{b}^{N *}>p_{b}^{D C *}>$ $p_{b}^{R *}>p_{b}^{M *}$.

Proof. Based on $\alpha^{N}<\alpha^{D C}=\alpha^{R}=\alpha^{M}=\alpha^{C}$ and $\beta^{N}<\beta^{D C}=$ $\beta^{R}=\beta^{M}=\beta^{C}$, we get $p^{D C *}-p^{M *}=T / 24>0$; therefore, $p^{D C *}>p^{M *}$; here, $T=\alpha^{k}-\theta c-c_{d}-\beta^{k} c_{b i}-\beta^{k} \theta c_{b} \cdot p^{M *}-$ $p^{R *}=T / 30>0$; thus, $p^{M *}>p^{R *} \cdot p^{D C *}-p^{M *}=\mathrm{T} / 24>0$; therefore, $p^{D C *}>p^{M *} \cdot p^{R *}-p^{C *}=3 T / 10>0$; thus, $p^{R *}>$ $p^{C *}$. When $p^{N *}-p^{D C *}>0$, we get $7\left(\alpha^{N}-\alpha^{D C}\right)+(1-\theta) c+$ $\left(\beta^{N}-\beta^{D C}\right) c_{b}-c_{d}>0$; thus, when $7\left(\alpha^{N}-\alpha^{D C}\right)+(1-\theta) c+$ $\left(\beta^{N}-\beta^{D C}\right) c_{b}-c_{d}>0, p^{N *}>p^{D C *}>p^{M *}>p^{R *}>p^{C *}$.

$w^{\mathrm{DC} *}-w^{M *}=3 T / 20$; thus, $w^{\mathrm{DC} *}>w^{M *} \cdot w^{M *}-w^{R *}=$ $T / 15>0$; thus, $w^{M *}>w^{R *}$. When, $w^{N *}-w^{\mathrm{DC} *}>0$, we get $3\left(\alpha^{N}-\alpha^{\mathrm{DC}}\right)+(1-\theta) c+\left(\beta^{N}-\beta^{\mathrm{DC}}\right) c_{b}-c_{d}>0$; thus, when $3\left(\alpha^{N}-\right.$ $\left.\alpha^{\mathrm{DC}}\right)+(1-\theta) c+\left(\beta^{N}-\beta^{\mathrm{DC}}\right) c_{b}-c_{d}>0, w^{N *}>w^{\mathrm{DC} *}>w^{M *}>$ $w^{R *}$.

$p_{b}^{\mathrm{DC} *}-p_{b}^{R *}=T / 10>0$; therefore, $p_{b}^{\mathrm{DC} *}>p_{b}^{R *} \cdot p_{b}^{R *}-$ $p_{b}^{M *}=T / 15>0$; thus, $p_{b}^{R *}>p_{b}^{M *}$. When $p_{b}^{N *}-p_{b}^{\mathrm{DC} *}>0$, we get $\beta^{\mathrm{DC}}\left(\alpha^{N}-c+\beta^{N} c_{b}\right)-\beta^{N}\left(\alpha^{\mathrm{DC}}-\theta c-c_{d}+\beta^{\mathrm{DC}} c_{b i}+\right.$ $\left.\beta^{\mathrm{DC}} \theta c_{b}\right)$; thus, when $\beta^{\mathrm{DC}}\left(\alpha^{N}-c+\beta^{N} c_{b}\right)-\beta^{N}\left(\alpha^{\mathrm{DC}}-\theta c-\right.$ $\left.c_{d}+\beta^{\mathrm{DC}} c_{b i}+\beta^{\mathrm{DC}} \theta c_{b}\right), p_{b}^{N *}>p_{b}^{\mathrm{DC} *}>p_{b}^{R *}>p_{b}^{M *}$. When $\beta^{\mathrm{DC}}\left(\alpha^{N}-c+\beta^{N} c_{b}\right)-\beta^{N}\left(\alpha^{\mathrm{DC}}-\theta c-c_{d}+\beta^{\mathrm{DC}} c_{b i}+\beta^{\mathrm{DC}} \theta c_{b}\right), p_{b}^{N *}>$ $p_{b}^{\mathrm{DC} *}>p_{b}^{R *}>p_{b}^{M *}$. Proposition 6 is confirmed.

Proposition 6 indicates that, in the $C$ model, the retail price is lowest. Due to the demand function $(Q=1-p / \alpha)$, in the $C$ model, the market demand is highest; therefore, it is more conducive for supply chain members to expand sales to get more revenues. In addition, the optimal wholesale price is highest in the $N$ model. In the $R$ model, the retailer has a stronger bargaining power and greater control ability, the lower the wholesale price, the higher the benefit space of the retailer. Finally, the optimal BDI retail price is highest in the $N$ model. In the $R$ and $M$ model, the retailer and the manufacturer have a stronger bargaining power and greater control ability; the lower the BDI retail price, the higher the benefit space of the retailer and the manufacturer.

Proposition 7. Benefits of supply chain members should meet the following relationships. When $\sqrt{\alpha^{N}}\left(\alpha^{D C}-\theta c-c_{d}+\beta^{D C} c_{b i}+\right.$ $\left.\beta^{D C} \theta c_{b}\right)-\sqrt{\alpha^{D C}}\left(\alpha^{N}-c+\beta^{N} c_{b}\right)>0, \pi_{r}^{R *}>\pi_{r}^{M *}>\pi_{r}^{D C *}>$
$\pi_{r}^{N *}, \pi_{d}^{M *}>\pi_{d}^{R *}>\pi_{d}^{D C *}>\pi_{d}^{N *}$, and $\pi^{C *}>\pi_{r}^{M *}+\pi_{d}^{M *}+$ $\pi_{b}^{M *}>\pi_{r}^{R *}+\pi_{d}^{R *}+\pi_{b}^{R *}>\pi_{r}^{D C *}+\pi_{b}^{D C *}+\pi_{d}^{D C *}>\pi_{r}^{N *}+\pi_{b}^{N *}+$ $\pi_{d}^{N *}$. When $4 \sqrt{2 \alpha^{N}}\left(\alpha^{R}-\theta c-c_{d}+\beta^{R} c_{b i}+\beta^{R} \theta c_{b}\right)-5 \sqrt{\alpha^{R}}\left(\alpha^{N}-\right.$ $\left.c+\beta^{N} c_{b}\right)>0, \pi_{b}^{D C *}>\pi_{b}^{M *}>\pi_{b}^{R *}>\pi_{b}^{N *}$.

Proof. Based on $\alpha^{N}<\alpha^{\mathrm{DC}}=\alpha^{R}=\alpha^{M}=\alpha^{\mathrm{C}}$ and $\beta^{N}<\beta^{\mathrm{DC}}=$ $\beta^{R}=\beta^{M}=\beta^{C}$, we get $\pi_{r}^{R *}-\pi_{r}^{M *}=T^{2} / 25 \alpha^{R}-T^{2} / 36 \alpha^{M}>0$ and $\pi_{r}^{M *}-\pi_{r}^{\mathrm{DC} *}=T^{2} / 36 \alpha^{M}-T^{2} / 64 \alpha^{\mathrm{DC}}>0$. When $\pi_{r}^{\mathrm{DC} *}-$ $\pi_{r}^{N *}>0$, we get $\sqrt{\alpha^{N}}\left(\alpha^{\mathrm{DC}}-\theta c-c_{d}+\beta^{\mathrm{DC}} c_{b i}+\beta^{\mathrm{DC}} \theta c_{b}\right)-$ $\sqrt{\alpha^{\mathrm{DC}}}\left(\alpha^{N}-c+\beta^{N} c_{b}\right)>0$. Thus, when $\sqrt{\alpha^{N}}\left(\alpha^{\mathrm{DC}}-\theta c-c_{d}+\right.$ $\left.\beta^{\mathrm{DC}} c_{b i}+\beta^{\mathrm{DC}} \theta c_{b}\right)-\sqrt{\alpha^{\mathrm{DC}}}\left(\alpha^{N}-c+\beta^{N} c_{b}\right)>0, \pi_{r}^{R *}>\pi_{r}^{M *}>$ $\pi_{r}^{\mathrm{DC} *}>\pi_{r}^{N *}$. Similarly, we get $\pi_{d}^{M *}-\pi_{d}^{R *}=T^{2} / 18 \alpha^{M}-T^{2} /$ $25 \alpha^{R}>0$ and $\pi_{d}^{R *}-\pi_{d}^{\mathrm{DC} *}=T^{2} / 25 \alpha^{R}-T^{2} / 32 \alpha^{\mathrm{DC}}>0$. When $\pi_{d}^{\mathrm{DC} *}-\pi_{d}^{N *}>0$, we get $\sqrt{\alpha^{N}}\left(\alpha^{\mathrm{DC}}-\theta c-c_{d}+\beta^{\mathrm{DC}} c_{b i}+\right.$ $\left.\beta^{\mathrm{DC}} \theta c_{b}\right)-\sqrt{\alpha^{\mathrm{DC}}}\left(\alpha^{N}-c+\beta^{N} c_{b}\right)>0$; thus, when $\sqrt{\alpha^{N}}\left(\alpha^{\mathrm{DC}}-\right.$ $\left.\theta c-c_{d}+\beta^{\mathrm{DC}} c_{b i}+\beta^{\mathrm{DC}} \theta c_{b}\right)-\sqrt{\alpha^{\mathrm{DC}}}\left(\alpha^{N}-c+\beta^{N} c_{b}\right)>0, \pi_{d}^{M *}>$ $\pi_{d}^{R *}>\pi_{d}^{\mathrm{DC} *}>\pi_{d}^{N *}$. Meanwhile, we get $\pi_{b}^{\mathrm{DC} *}-\pi_{b}^{M *}=T^{2} /$ $16 \alpha^{\mathrm{DC}}-T^{2} / 18 \alpha^{M}>0$ and $\pi_{b}^{M *}-\pi_{b}^{R *}=T^{2} / 18 \alpha^{M}-T^{2} / 25 \alpha^{R}>$ 0 . When $\pi_{b}^{R *}-\pi_{b}^{N *}>0$, we get $4 \sqrt{2 \alpha^{N}}\left(\alpha^{R}-\theta c-c_{d}+\right.$ $\left.\beta^{R} c_{b i}+\beta^{R} \theta c_{b}\right)-5 \sqrt{\alpha^{R}}\left(\alpha^{N}-c+\beta^{N} c_{b}\right)>0$. Therefore, when $4 \sqrt{2 \alpha^{N}}\left(\alpha^{R}-\theta c-c_{d}+\beta^{R} c_{b i}+\beta^{R} \theta c_{b}\right)-5 \sqrt{\alpha^{R}}\left(\alpha^{N}-c+\beta^{N} c_{b}\right)>0$, $\pi_{b}^{\mathrm{DC} *}>\pi_{b}^{M *}>\pi_{b}^{R *}>\pi_{b}^{N *}$. In addition, $\pi_{r}^{M *}+\pi_{d}^{M *}+\pi_{b}^{M *}=$ $5 T^{2} / 36 \alpha^{M}, \pi_{r}^{R *}+\pi_{d}^{R *}+\pi_{b}^{R *}=3 T^{2} / 25 \alpha^{R}$, and $\pi_{r}^{\mathrm{DC} *}+\pi_{b}^{\mathrm{DC} *}+$ $\pi_{d}^{\mathrm{DC} *}=7 T^{2} / 64 \alpha^{\mathrm{DC}}, \pi_{r}^{N *}+\pi_{b}^{N *}+\pi_{d}^{N *}=7\left(\alpha^{N}-c-\beta^{N} c_{b}\right)^{2} /$ $64 \alpha^{N}$; by comparing, we get that when $\sqrt{\alpha^{N}}\left(\alpha^{\mathrm{DC}}-\theta c-\right.$ $\left.c_{d}+\beta^{\mathrm{DC}} c_{b i}+\beta^{\mathrm{DC}} \theta c_{b}\right)-\sqrt{\alpha^{\mathrm{DC}}}\left(\alpha^{N}-c+\beta^{N} c_{b}\right)>0, \pi^{\mathrm{C} *}>$ $\pi_{r}^{M *}+\pi_{d}^{M *}+\pi_{b}^{M *}>\pi_{r}^{R *}+\pi_{d}^{R *}+\pi_{b}^{R *}>\pi_{r}^{\mathrm{DC} *}+\pi_{b}^{\mathrm{DC} *}+\pi_{d}^{\mathrm{DC} *}>$ $\pi_{r}^{N *}+\pi_{b}^{N *}+\pi_{d}^{N *}$. Thus, Proposition 7 is proved.

Proposition 7 indicates that the retailer's benefit in the $R$ model is highest in the models of DC, $R, N$, and $M$. The manufacturer's revenue in the $M$ model is highest in the models of DC, $R, N$, and $M$. Benefit of the Data Company in the DC model is highest in the models of DC, $N, R$, and $M$. These demonstrate that the first mover has more advantages in the process of game. Namely, if supply chain members who want to gain more benefits should become the first mover, to the entire supply chain, the benefit of the entire supply chain in the $C$ model is highest among the four models. However, in the decentralized decision supply chain, the benefit of supply chain in the $M$ model is highest in the three models. When we only consider the manufacturer and the retailer, we can find if one supply chain member is the game leader and has applied Big Data plan to obtain more benefits; benefits of the entire supply chain will be higher.

\section{Numerical Simulation}

In this chapter, a numerical example will be presented to show the results' effectiveness. In reality, the value of $\theta$ is difficult to measure, and it is related to the costs improved by using BDI. Based on our survey in many companies who have applied Big Data plan, they say that their benefits do increase after using Big Data. Moreover, based on what is below analyzed, we can get that, as long as the application of 


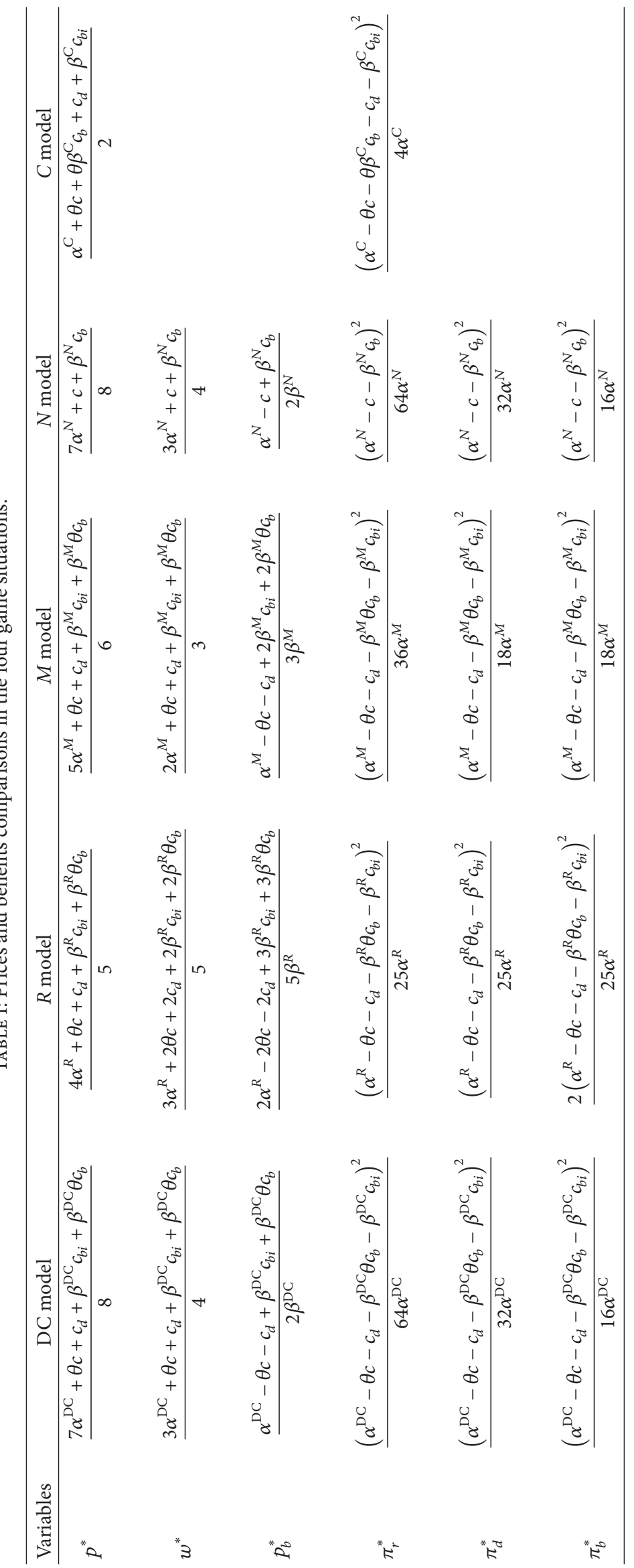




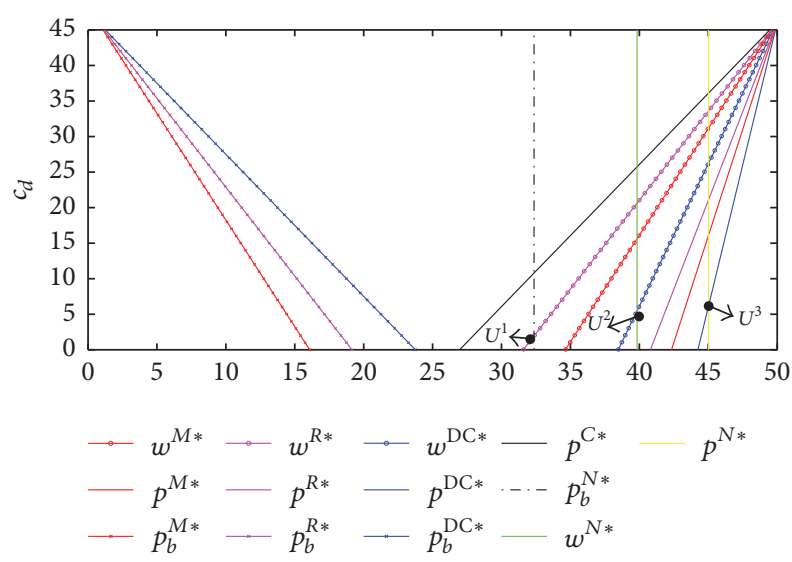

FIGURE 2: Effects of $c_{d}$ on pricing strategies of supply chain members.

Big Data is effective in reducing production costs, benefits of supply chain members will increase.

According to document [39] and the range of $\theta$, we set $\theta=0.65$. Based on our actual survey in a book publishing company (this company designs and makes books based on consumer BDI and it gains the related consumer BDI from a Data Company) from Chongqing, China, we choose a best seller as the test subject and its retailer price is 25. According to formula (1), $\alpha^{k}$ should be bigger than 25; thus, based on Section 3.2.2, without losing generality, we set $\alpha^{N}=40<$ $\alpha^{\mathrm{DC}}=\alpha^{R}=\alpha^{M}=\alpha^{C}=50$. Based on our actual survey, we set $c=5$ and $c_{b}=1$. According to the range of $\beta^{k}$ and Section 3.2.2, without losing generality, we set $\beta^{N}=0.7<$ $\beta^{\mathrm{DC}}=\beta^{R}=\beta^{M}=\beta^{C}=0.9$. According to formulas (8), (13), and (19), $c_{b i}+c_{d}<4.61$. Without losing generality, let $c_{b i}=0.1$.

Effects of the internal BDI investment cost of the manufacturer $\left(c_{d}\right)$ on the pricing strategies of supply chain members in the five models are shown in Figure 2. From Figure 2, we can get that, with the increase of the internal BDI investment cost of the manufacturer $\left(c_{d}\right)$, the optimal retail price of the Data Company in models of DC, $R$, and $M$ will decrease, and the optimal wholesale price in models of DC, $R$, and $M$ will grow, and the optimal product retail price in models of DC, $R, M$, and $C$ will increase. However, the prices of supply chain members in the $N$ model will not be influenced by $c_{d}$. According to Figure 2, we can also get that the optimal retail price of the Data Company in the DC model is higher than it is in the $R$ model, and in the $R$ model is higher than it is in the $M$ model. The optimal product retail price in the $C$ model is smallest in the four models. The optimal wholesale price in the $M$ model is higher than it is in the $R$ model and lower than it is in the DC model. When the value of $c_{d}$ is low, $U^{1}, U^{2}$, and $U^{3}$, the BDI retail price, the product retail price, and the wholesale price in the $N$ model are highest among the five models, respectively. Thus, (2) in Proposition 1, (2) in Proposition 2, (2) in Proposition 3, and Proposition 5 are confirmed.

Effects of the internal BDI investment cost of the manufacturer $\left(c_{d}\right)$ on the benefits of supply chain members in models of DC, $N, R$, and $M$ are shown in Figure 3. From

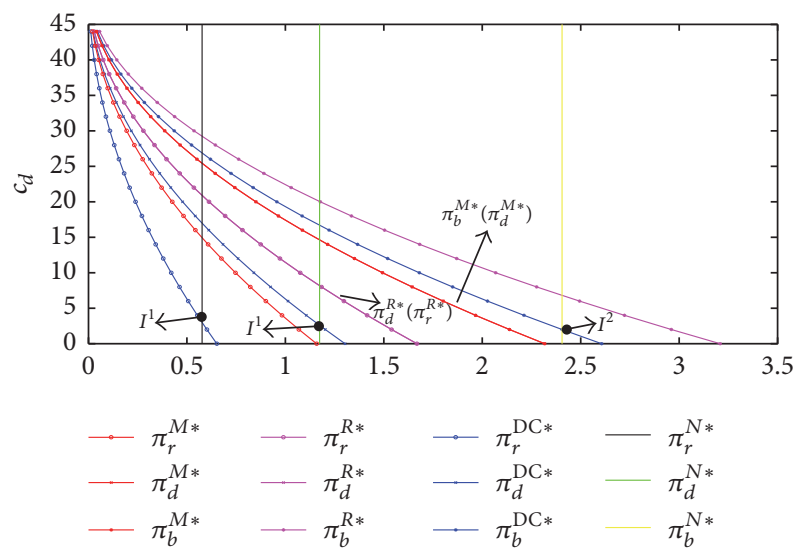

FIGURE 3: Effects of $c_{d}$ on benefits of supply chain members.

Figure 3, we can get that, with the increase of $c_{d}$, the benefits of supply chain members in models of DC, $R$, and $M$ will decrease. However, the benefits of supply chain members in the $N$ model will not be influenced by $c_{d}$. In addition, the optimal benefits of the retailer in the $R$ model is highest among the three models, and the optimal revenues of the manufacturer in the $M$ model are highest among the three models, and the optimal profits of the Data Company in the DC model are highest in the three models. It indicates who is the game leader and who will gain more benefits. In addition, in the $M$ model, benefits of the Data Company and the manufacturer are the same. In the $R$ model, revenues of the manufacturer and the retailer are the same. When the value of $c_{d}$ is low, $I^{2}$, benefits of supply chain members in the $N$ model are lowest among the five models. Moreover, in models of DC, $R$, and $M$, revenues of the manufacturer and the Data Company are higher than benefits of the retailer. It proves the rule "who will gain benefit from his/her investment" [32].

Effects of $c_{b i}$ on the pricing strategies of supply chain members in models of DC, $N, R, M$, and $C$ are shown in Figure 4. From Figure 4, we can get that, when $c_{b i}<G$, with the increase of $c_{b i}$, the optimal retail price of the Data Company, the optimal product retail price, and the optimal wholesale price will grow. However, the prices of supply chain members in the $N$ model will not be influenced by $c_{b i}$. According to Figure 4, we can also get that the optimal retail price of the Data Company in the DC model is highest among the four models. The optimal product retail price in the $C$ model is smallest among the four models. When the value of $c_{b i}$ is low $L^{2}$, prices of supply chain members in the $N$ model are highest among the five models. The optimal wholesale price in the $M$ model is higher than it is in the $R$ model and lower than it is in the DC model. Thus, (1) in Proposition 1, (1) in Proposition 2, and (1) in Proposition 3 are confirmed.

Effects of $c_{b i}$ on benefits of supply chain members in the models of DC, $N, R$, and $M$ are shown in Figure 5. From Figure 5, we can get that, with the increase of $c_{b i}$, the benefits of supply chain members in models of DC, $R$, and $M$ will decrease. However, the benefits of supply chain members in the $N$ model will not be influenced by $c_{b i}$. In addition, the optimal benefit of the retailer in the $R$ model is highest 


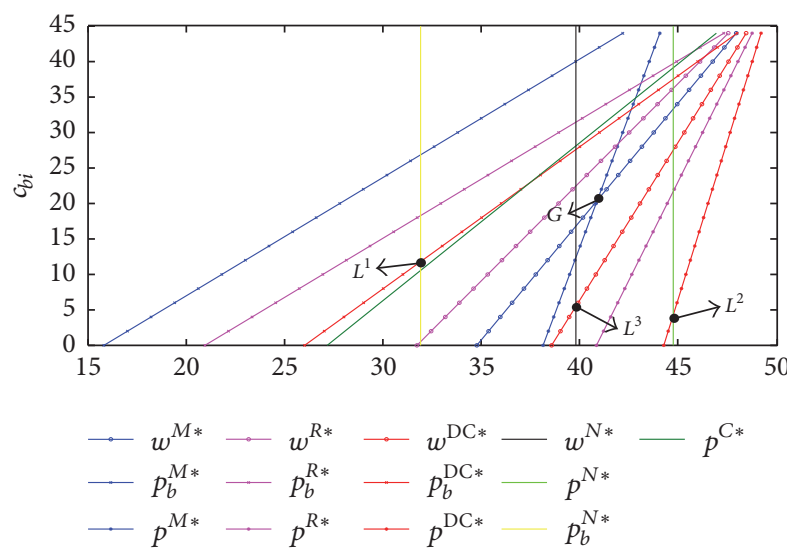

FIGURE 4: Effects of $c_{b i}$ on the pricing strategies of supply chain members.

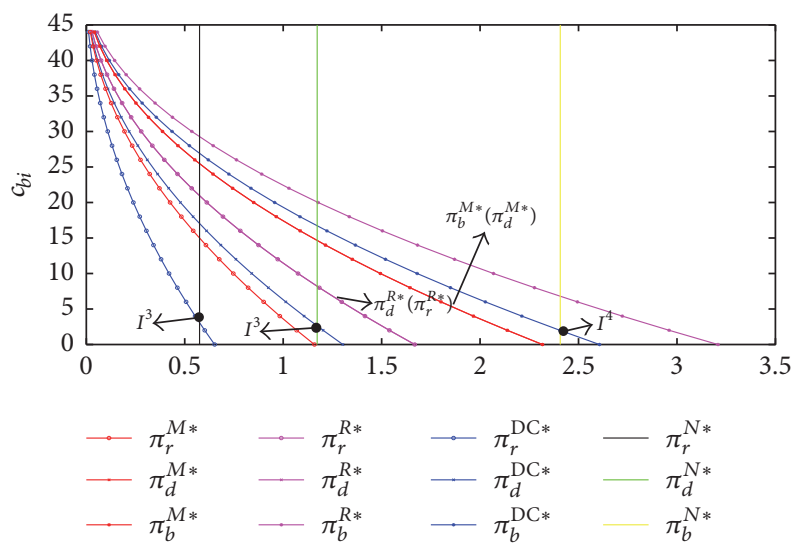

FIGURE 5: Effects of $c_{b i}$ on the benefits of supply chain members.

among the three models, and the optimal revenues of the manufacturer in the $M$ model are highest among the three models, and the optimal profits of the Data Company in the DC model are highest in the three models. It indicates who are the game leader and who will gain more benefits. In addition, in the $R$ model, the optimal benefits of the retailer and the manufacturer are the same. In the $M$ model, benefits of the Data Company and the manufacturer are the same. Moreover, in models of DC, $R$, and $M$, revenues of the manufacturer and the Data Company are higher than benefits of the retailer. When the value of $c_{b i}$ can be low, $I^{4}$, benefits of supply chain members in the $N$ model are lowest among the five models.

Effects of the industry cost improvement coefficient $(\theta)$ on the pricing strategies of supply chain members in models of DC, $R, N$, and $M$ are shown in Figure 6. However, the prices of supply chain members in the $N$ model will not be influenced by $\theta$. From Figure 6, we can get that, with the increase of $\theta$, the optimal retail price of the Data Company in the three models will decrease, and the optimal wholesale price and the optimal product retail price in the three models will grow. According to Figure 6, we can also get that the optimal retail price of the Data Company in the DC model is highest among the three models. The optimal product retail price in the $R$ model is smallest among the three models. The optimal wholesale price in the $M$ model is higher than it is in the $R$ model and lower than it is in the DC model. Prices of supply chain members in the $N$ model are highest among the five models, when $\theta$ is in its range. Thus, (3) in Proposition 1, (3) in Proposition 2, and (3) in Proposition 3 are confirmed.

Effects of the industry cost improvement coefficient $(\theta)$ on benefits of supply chain members in models of DC, $R, N$, and $M$ are shown in Figure 7. From Figure 7, we can get that, with the increase of $\theta$, benefits of supply chain members in the three models will decrease. However, the benefits of supply chain members in the $N$ model will not be influenced by $\theta$. In addition, the optimal benefits of the retailer in the $R$ model are highest in the three models, and the optimal revenues of the manufacturer in the $M$ model is highest among the three models, and the optimal profits of the Data Company in the DC model are highest in the three models. It indicates who are the game leader and who will gain more benefits. In addition, in the $R$ model, the optimal benefits of the retailer and the manufacturer are the same. In the $M$ model, benefits of the Data Company and the manufacturer are the same. Moreover, in models of DC, $R$, and $M$, revenues of the manufacturer and the Data Company are higher than benefits of the retailer. When the value of $\theta$ can be low, $K^{1}$, benefits of supply chain members in the $N$ model are lowest among the five models.

Effects of $\theta, c_{b i}$, and $c_{d}$ on benefits of the entire supply chain in the proposed five models are shown in Figure 8. From Figure 8, we can get that, with the growth of $\theta, c_{b i}$, and $c_{d}$, benefits of the entire supply chain will reduce excepting it in the $N$ model. Moreover, in the centralized supply chain, benefit of supply chain is highest. When we only consider the decentralized supply chain, benefit of supply chain in the $M$ model is highest. These demonstrate that, in the centralized game situation, supply chain can get more benefits; thus, decision-makers should try their best to coordinate members in the supply chain. If decision-makers cannot coordinate other members well, manufacturer as the game leader will be good to other supply chain members. Moreover, when the values of $\theta, c_{b i}$, and $c_{d}$ are low, $J^{1}, J^{2}$, and $J^{3}$, respectively, benefits of supply chain in the $N$ model are lowest. In summary, based on Figures 7 and 8, Proposition 7 is proved.

Based on the above analyses, we can also get that if the manufacturer has the ability to collect, store, and deal with Big Data, when these costs face a certain range, it should be good for the manufacturer to own the Big Data.

\section{Conclusions and Significance}

6.1. Conclusions. In the Big Data era, Data Company as a provider of BDI is playing an increasingly important role in a supply chain. Many companies start to gain related BDI from it. However, getting BDI from a Data Company will increase companies' extra money; meanwhile, getting the accurate and timely consumer preference BDI will also add the Data Company's extra money to improving new data analysis technology and equipment. In this process, the previous pricing rules are not suitable in the new environment; thus, finding the pricing rules in the new environment is important for supply chain members. However, Data Company as a vital 


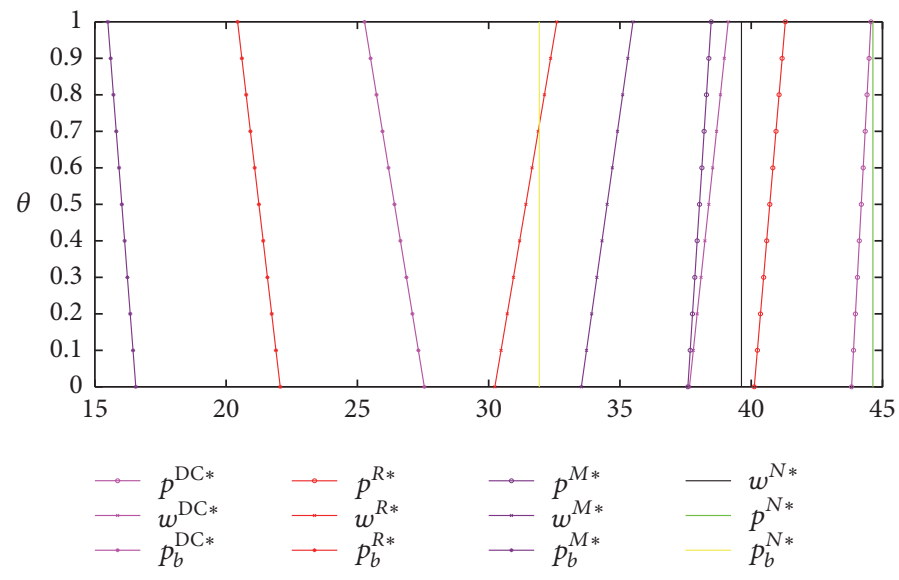

FIGURE 6: Effects of $\theta$ on the pricing strategies of supply chain members.

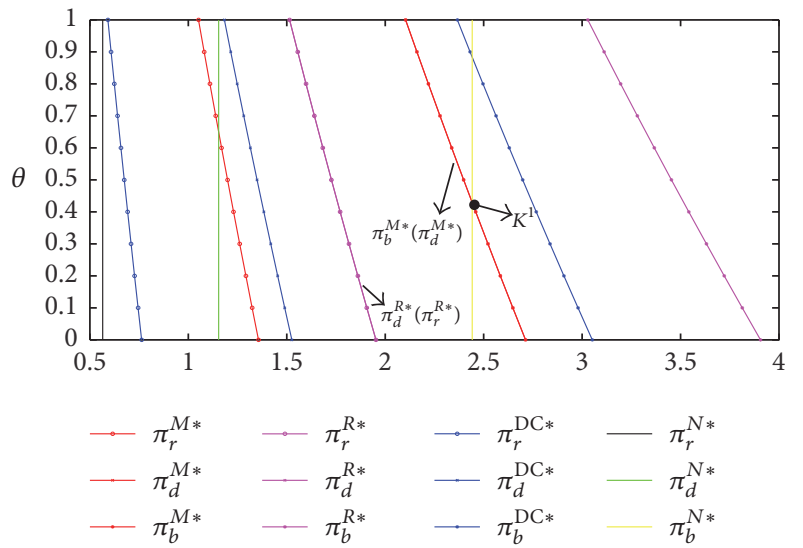

Figure 7: Effects of $\theta$ on benefits of supply chain members.

role in a supply chain is seldom considered in researching pricing rules in previous researches. Therefore, in this study, a supply chain with one manufacturer, one retailer, and one Data Company is chosen. Then, four benefit models are constructed. By analyzing the above models, we get some results.

(1) The industry cost improvement coefficient $(\theta)$, the internal BDI investment cost of the manufacturer $\left(c_{d}\right)$, and the added cost of the Data Company on using Big Data technology $\left(c_{b i}\right)$ have a positive relationship with the optimal wholesale price and the optimal product retail price in models of DC, $R$, and $M$.

Namely, in the decentralized supply chain, no matter who is the game leader, and the fact that manufacturer and Data Company invest and use Big Data will make product's wholesale price and retail price increase. For manufacturer, it should try its best to reduce BDI investment cost (this is related to the negotiation level of manufacturer) and extract the value of BDI to face consumer demand. Then, the wholesale price and the product retail price may reduce.

(2) The added cost of the Data Company on using Big Data technology $\left(c_{b i}\right)$ has a positive relationship with the optimal retail price of the Data Company, and the industry cost improvement coefficient $(\theta)$ and the internal BDI investment cost of the manufacturer $\left(c_{d}\right)$ has a negative relationship with the optimal retail price of the Data Company.

In other words, no matter who is the game leader, investing and using new data analysis technology will add to the retail price of Data Company. If the manufacturer wants to get a lower consumer BDI price, it should invest and use its internal BDI and try its best to extract the value of BDI to reduce its production costs and face consumer demand.

(3) In the $C$ model, the optimal product retail price is smallest among the four models. The optimal wholesale price in the $M$ model is higher than it is in the $R$ model and lower than it is in the DC model. In the DC model, the optimal retail price of the Data Company is biggest in the three models.

Namely, in the $C$ model, the decision-maker can set a lower retail price to gain more benefits. If the manufacturer wants to gain more benefits, it should master the initiative in the game process and set a high wholesale price. Similarly, if the Data Company wants to get more revenues, it should also master the initiative in the game process and set a high retail price.

(4) The industry cost improvement coefficient $(\theta)$, the internal BDI investment cost of the manufacturer $\left(c_{d}\right)$, and the added cost of the Data Company on using Big Data technology $\left(c_{b i}\right)$ have a negative relationship with the benefits of supply chain members in models of DC, $R$, and $M$. In addition, in the $R$ model, the optimal benefits of the retailer and the manufacturer are the same, and, in the $M$ model, benefits of the Data Company and the manufacturer are the same. The optimal benefits of the Data Company are biggest among the three members in models of DC, $R$, and $M$.

In other words, if supply chain members want to get more benefits, the manufacturer should try its best to reduce its internal BDI acquisition costs and the Data Company should also try its best to reduce its Big Data investment. Meanwhile, BDI users should try their best to extract BDI value to make consumer needed product as much as possible.

(5) With the growth of the consumer preference information conversion coefficient $\beta^{k}$, the wholesale price, the product retail price, and the retail price of Data Company will increase, and benefits of supply chain members will reduce. 


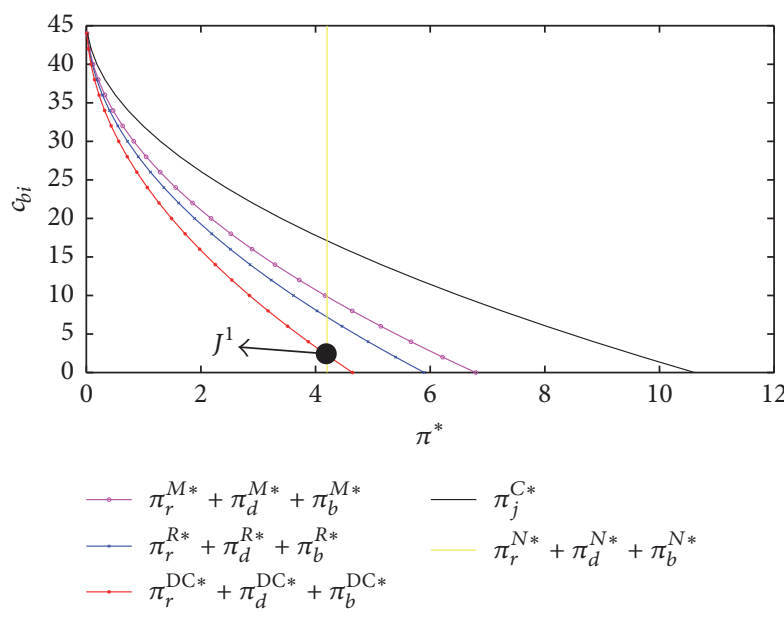

(a)

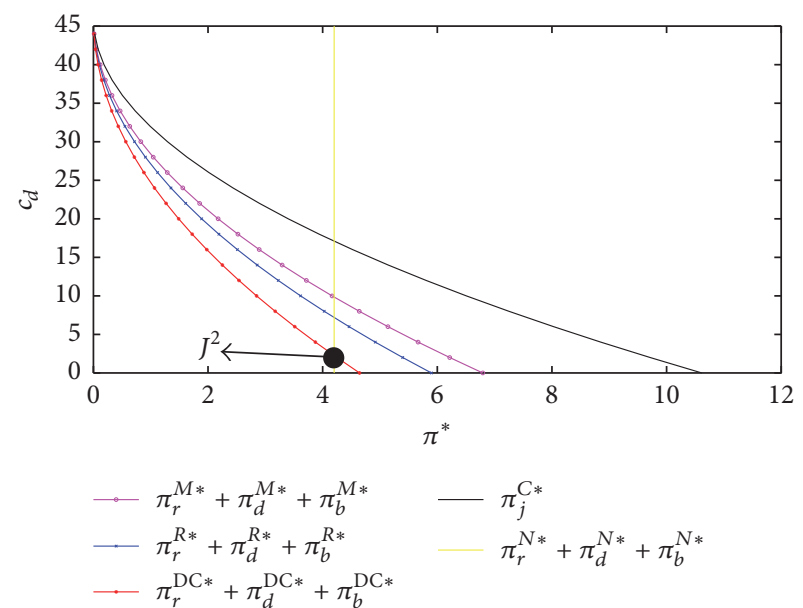

(b)

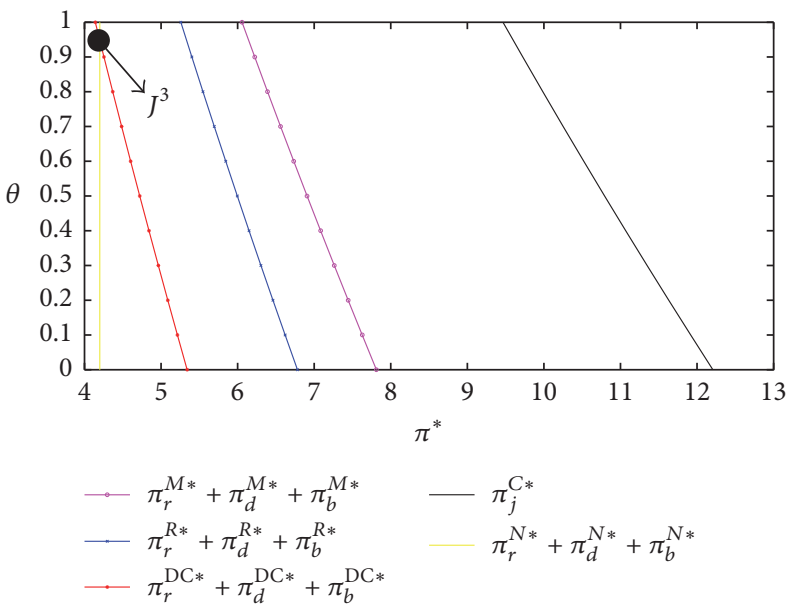

(c)

Figure 8: Effects of $\theta, c_{b i}$, and $c_{d}$ on benefits of the entire supply chain.

Namely, if supply chain members want to gain best benefits, the consumer preference information conversion coefficient $\beta^{k}$ should be reduced. If $\beta^{k}$ can equal 1 (i.e., $=Q$ ), all the information purchased by the manufacturer can be used fully and supply chain members can gain an optimal revenues. It illustrated that the application ability of BDI is important for users, and they should try their best to extract the value of BDI and use it to make consumer demand products.

6.2. Significance. This study has some new contributions. Theoretically, pricing strategies of supply chain in the Big Data environment were studied considering the Data Company, and four benefit models were proposed. The optimal pricing strategies and benefits in the four models were compared. This research is a new development of pricing strategies theory of supply chain in the Big Data environment. It offers a theoretical guidance for Data Company, retailer, and manufacturer for setting their optimal prices to gain more benefits.

\section{Limitations and Future Research}

7.1. Limitations. This paper only studies a three-stage supply chain system with one manufacturer, one Data Company, and one retailer. In fact, a supply chain system is very complex; there are double channel and multichannel supply chains. Moreover, in a supply chain system, it contains supplier, manufacturer, retailer, and third-party logistics; however, in this paper, only the relationships among manufacturer, Data Company, and retailer are discussed. In addition, supply chain members are assumed to be riskneutral.

7.2. Future Research. In the future, the pricing policies of a supply chain should be studied with a multichannel supply chain or a multistage supply chain in the Big Data environment. In addition, next, a three-stage supply chain with members having risk appetite should be discussed. We can also explore the related questions in different competitive environments. 


\section{Variables and Parameters}

$p^{k}$ : It is the product retail price in different models. Here, $k=\{N, \mathrm{DC}, R, M, C\} . N$ model stands for the condition of no supply chain members investing in Big Data. DC model stands for Data Company-dominated supply chain model. $R$ model presents retailer-dominated supply chain model. $M$ model stands for manufacturer-dominated supply chain model. $C$ model presents the centralized model.

$p_{b}^{k}$ : It shows the BDI or information retail price in different models.

$\alpha^{k}$ : It is the value discount factor and is influenced by the precision of consumer preference information.

$c_{b}$ : It expresses the information production cost of the Data Company.

$c_{b i}$ : It is the added costs of the Data Company because of gaining Big Data and using Big Data technology to gain BDI.

$c$ : It stands for the product production cost of the manufacturer.

$c_{d}$ : It represents the internal BDI cost of the manufacturer.

$w^{k}:$ It is the wholesale price of the product in different models.

$\theta:$ It expresses "the industry cost improvement coefficient. By analyzing the internal and external BDI of a company and using it in company can help reduce the company's cost" [32]. Here, $\theta \in[0,1]$ Then, $c$ and $c_{b}$ can be improved to $\theta c$ and $\theta c_{b}$

$\pi_{b}^{k}$ : It represents benefits of Data Company in different models.

$\pi_{r}^{k}$ : It stands for revenues of the retailer in different models.

$\pi_{d}^{k}$ : It is benefits of the manufacturer in different models.

$v$ : It stands for the perceived value of consumer on product; here, $v \in[0,1]$

$Q^{k}$ : It expresses the actual market demand in different models.

$D^{k}$ : It stands for the total number of consumer information the manufacturer brought from Data Company in different models.

$\beta^{k}$ : It shows the consumer preference information conversion coefficient in different models; here, $\beta^{k} \geq 1$.

\section{Conflicts of Interest}

The author declares that there are no conflicts of interest.

\section{Authors' Contributions}

Pan Liu conceived, designed, and performed the experiments; Pan Liu analyzed the data and wrote the paper.

\section{References}

[1] E. Cambria, T. Mazzocco, and A. Hussain, "Application of multidimensional scaling and artificial neural networks for biologically inspired opinion mining," Biologically Inspired Cognitive Architectures, vol. 4, pp. 41-53, 2013.

[2] X.-B. Huang and H.-X. Zhong, "Build enterprise competitive intelligence system model based on Big Data," Journal of Intelligence, vol. 03, pp. 37-43, 2013.

[3] N. R. Sanders, Big Data Driven Supply Chain Management, China Ren Min University Press, 2015.

[4] D. Barton, "Making advanced analytics work for you," Harvard Business Review, vol. 38, no. 90, pp. 78-128, 2012.

[5] A. McAfee, "Big data: the management revolution," Harvard Business Review, vol. 10, no. 90, pp. 68-128, 2012.

[6] B. K. Chae and D. L. Olson, "Business analytics for supply chain: a dynamic-capabilities framework," International Journal of Information Technology \& Decision Making, vol. 12, no. 1, pp. 926, 2013.

[7] B. T. Hazen, C. A. Boone, J. D. Ezell, and L. A. Jones-Farmer, "Data quality for data science, predictive analytics, and big data in supply chain management: An introduction to the problem and suggestions for research and applications," International Journal of Production Economics, vol. 154, pp. 72-80, 2014.

[8] P. Trkman, K. McCormack, M. P. V. De Oliveira, and M. B. Ladeira, "The impact of business analytics on supply chain performance," Decision Support Systems, vol. 49, no. 3, pp. 318327,2010

[9] M. A. Waller and S. E. Fawcett, "Data science, predictive analytics, and big data: a revolution that will transform supply chain design and management," Journal of Business Logistics, vol. 34, no. 2, pp. 77-84, 2013.

[10] D. Dutta and I. Bose, "Managing a big data project: The case of Ramco cements limited," International Journal of Production Economics, vol. 165, article no. 5962, pp. 293-306, 2015.

[11] K. H. Tan, Y. Z. Zhan, G. Ji, F. Ye, and C. Chang, "Harvesting big data to enhance supply chain innovation capabilities: an analytic infrastructure based on deduction graph," International Journal of Production Economics, vol. 165, pp. 223-233, 2015.

[12] Z. Bi and D. Cochran, "Big data analytics with applications," Journal of Management Analytics, vol. 1, no. 4, pp. 249-265, 2015.

[13] S. Fosso Wamba, S. Akter, A. Edwards, G. Chopin, and D. Gnanzou, "How 'big data' can make big impact: Findings from a systematic review and a longitudinal case study," International Journal of Production Economics, vol. 165, article no. 5961, pp. 234-246, 2015.

[14] M. Janssen, H. van der Voort, and A. Wahyudi, "Factors influencing big data decision-making quality," Journal of Business Research, vol. 70, pp. 338-345, 2017.

[15] S. F. Wamba, A. Gunasekaran, S. Akter, S. J.-F. Ren, R. Dubey, and S. J. Childe, "Big data analytics and firm performance: Effects of dynamic capabilities," Journal of Business Research, vol. 70, pp. 356-365, 2017.

[16] A. Gunasekaran, T. Papadopoulos, R. Dubey et al., "Big data and predictive analytics for supply chain and organizational performance," Journal of Business Research, 2016.

[17] S. Akter, S. F. Wamba, A. Gunasekaran, R. Dubey, and S. J. Childe, "How to improve firm performance using big data analytics capability and business strategy alignment?" International Journal of Production Economics, vol. 182, pp. 113-131, 2016. 
[18] E. Hofmann, "Big data and supply chain decisions: the impact of volume, variety and velocity properties on the bullwhip effect," International Journal of Production Research, pp. 1-19, 2017.

[19] M. Brinch, J. Stentoft, and J. K. Jensen, "Big Data and its Applications in Supply Chain Management: Findings from a Delphi Study," in Proceedings of the Hawaii International Conference on System Sciences, 2017.

[20] K. Lamba and S. P. Singh, "Big data in operations and supply chain management: current trends and future perspectives," Production Planning and Control, vol. 28, pp. 877-890, 2017.

[21] B. Niu and Z. Zou, "Better demand signal, better decisions? evaluation of big data in a licensed remanufacturing supply chain with environmental risk considerations," Risk Analysis, vol. 3, 2017.

[22] R. Chavez, W. Yu, M. A. Jacobs et al., "Data-driven supply chains, manufacturing capability and customer satisfaction," Production Planning and Control, vol. 28, pp. 11-12, 2017.

[23] G. Ji, L. Hu, and K. H. Tan, "A study on decision-making of food supply chain based on big data," Journal of Systems Science and Systems Engineering, vol. 26, no. 2, pp. 1-16, 2017.

[24] T. Badiezadeh, R. F. Saen, and T. Samavati, "Assessing sustainability of supply chains by double frontier network DEA: A big data approach," Computers Operations Research, pp. 1-22, 2017.

[25] U. K. Mukherjee and K. K. Sinha, "Product recall decisions in medical device supply chains: a big data analytic approach to evaluating judgment bias," Production Engineering Research and Development, pp. 1-20, 2017.

[26] V. Mani, C. Delgado, B. Hazen, and P. Patel, "Mitigating supply chain risk via sustainability using big data analytics: evidence from the manufacturing supply chain," Sustainability, vol. 608, no. 9, pp. 1-21, 2017.

[27] W. Yu, R. Chavez, M. A. Jacobs et al., "Data-driven supply chain capabilities and performance: A resource-based view," Transportation Research Part E Logistics Transportation Review, pp. 1-24, 2017.

[28] M. M. Olama, A. W. McNair, S. R. Sukumar, and J. J. Nutaro, "A qualitative readiness-requirements assessment model for enterprise big-data infrastructure investment," International Society for Optics and Photonics, vol. 9122, 2014.

[29] P. Tambe, "Big data investment, skills, and firm value," Management Science, vol. 60, no. 6, pp. 1452-1469, 2014.

[30] H. Shi and J. Li, "effect of private information leakage on competition relationship among supply chain enterprises in big data era[J]," Journal of the China Society for Scientific andTechnical Information, vol. 1, pp. 53-65, 2015.

[31] C.-X. Wu, D.-Z. Zhao, and X.-Y. Pan, "Comparison on dynamic cooperation strategies of a three-echelon supply chain involving big data service provider," Control and Decision, vol. 31, no. 7, pp. 1169-1177, 2016.

[32] P. Liu and S.-P. Yi, "A study on supply chain investment decision-making and coordination in the Big Data environment," Annals of Operations Research, pp. 1-19, 2017.

[33] P. Liu and S.-p. Yi, "Investment decision-making and coordination of supply chain: a new research in the big data era," Discrete Dynamics in Nature and Society, Article ID 2026715, Art. ID 2026715, 10 pages, 2016.

[34] W. Baker and D. Kiewell, Using Big Data to Make Better Pricing Decisions, vol. 27, McKinsey and Company, 2014.

[35] P. Liu and S. Yi, "Pricing policies of green supply chain considering targeted advertising and product green degree in the Big Data environment," Journal of Cleaner Production, vol. 164, pp. 1614-1622, 2017.
[36] G. Li, H. Mao, and L. Xiao, "Impacts of leader-follower structure on pricing and production strategies in a decentralized assembly system," Asia-Pacific Journal of Operational Research, vol. 34, no. 1, Article ID 1740003, 1740003, 24 pages, 2017.

[37] G. Ferrer and J. M. Swaminathan, "Managing new and remanufactured products," Management Science, vol. 52, no. 1, pp. 1526, 2006.

[38] P. Gao, X. Wang, Y. Jing, and L. Deng, "Differential price strategies between remanufactured products with refurbished products based on heterogeneous demands," Computer Integrated Manufacturing Systems, vol. 20, no. 9, pp. 2134-2145, 2014.

[39] M. A. Hernandez, "Nonlinear pricing and competition intensity in a Hotelling-type model with discrete product and consumer types," Economics Letters, vol. 110, no. 3, pp. 174-177, 2011. 


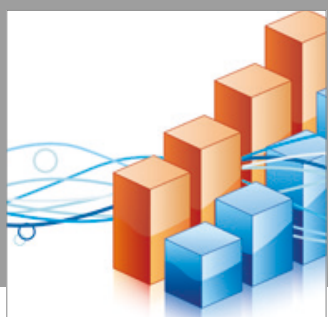

Advances in

Operations Research

vatersals

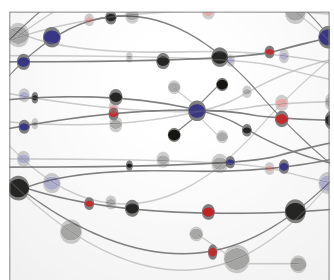

\section{The Scientific} World Journal
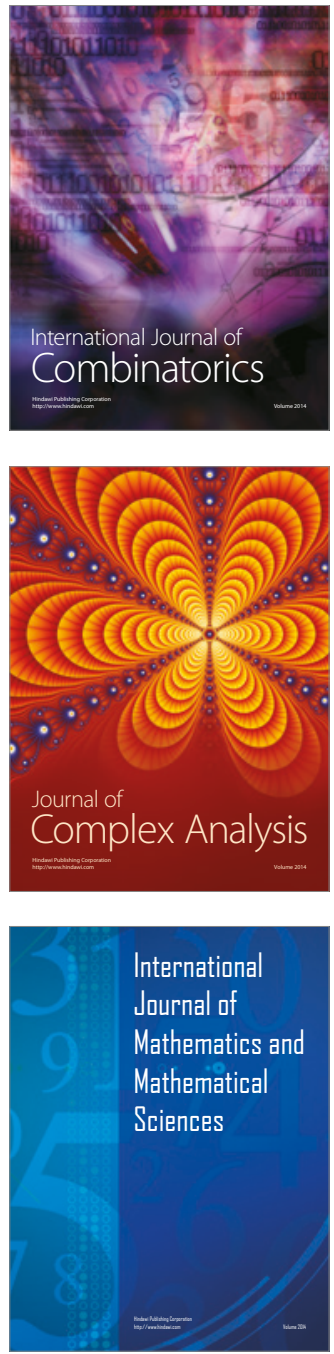
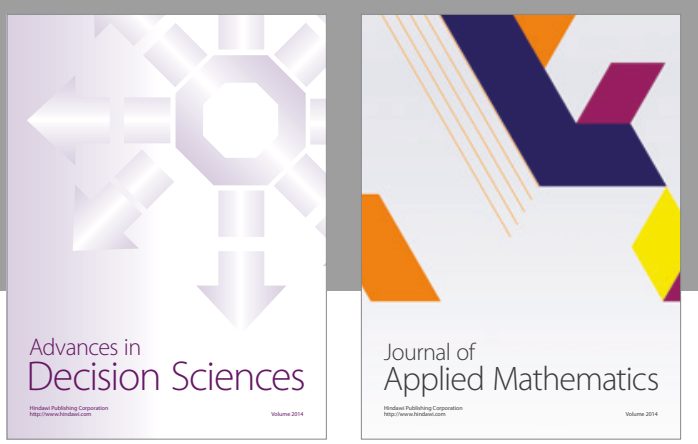

Algebra

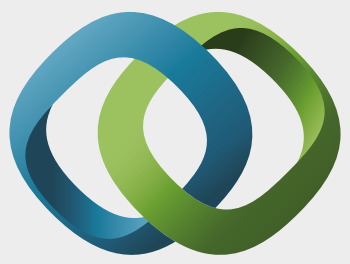

\section{Hindawi}

Submit your manuscripts at

https://www.hindawi.com
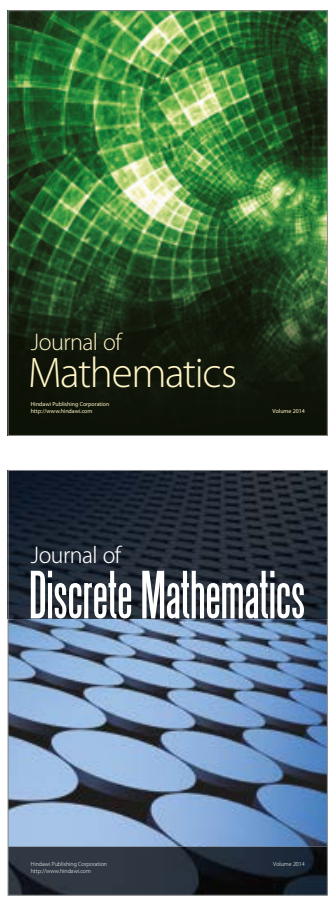

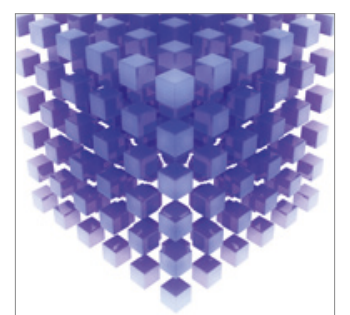

Mathematical Problems in Engineering
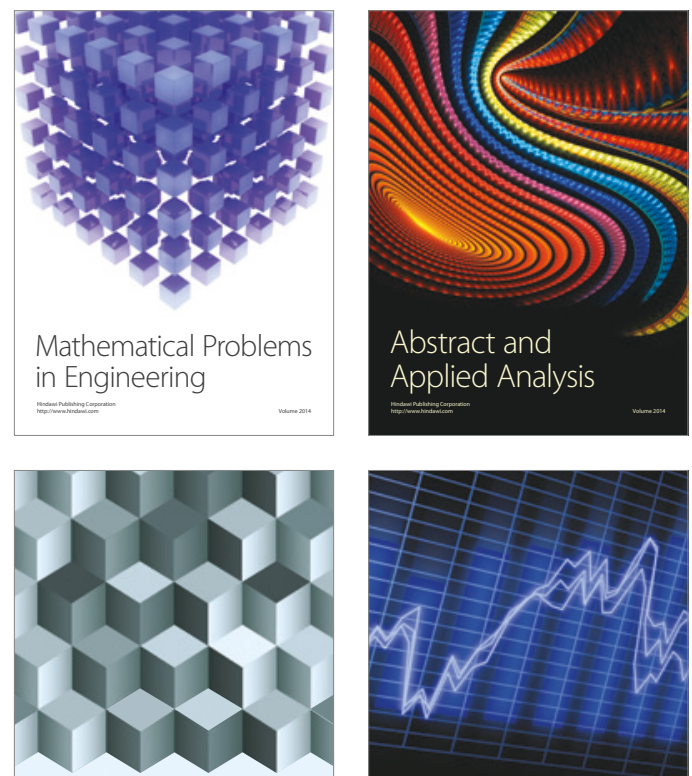

Journal of

Function Spaces

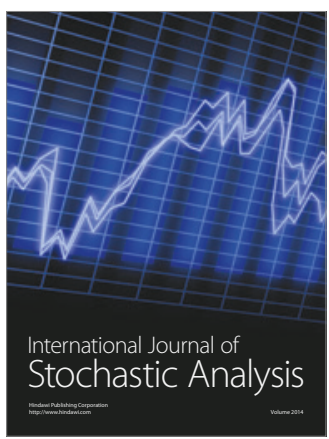

Probability and Statistics
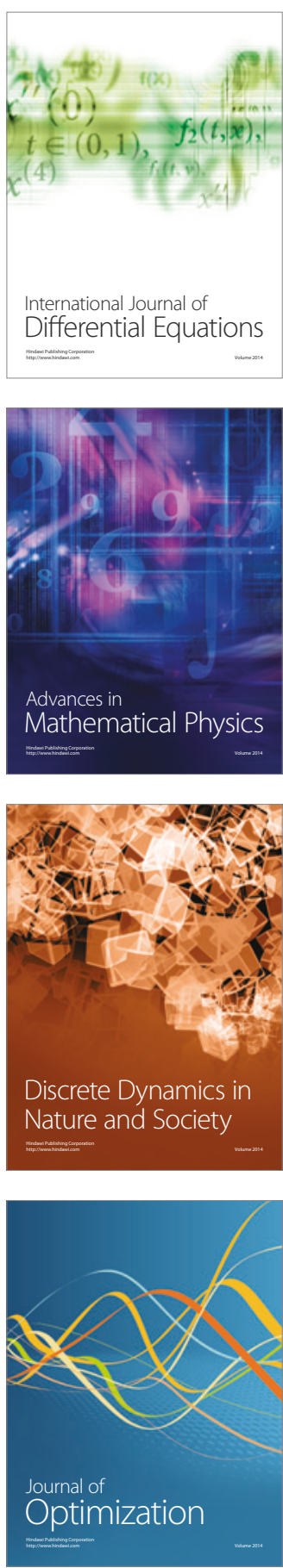